\title{
Assessing Absolute and Relative Pro-poor Growth, with an Application to Selected African Countries
}

\author{
Sami Bibi \\ Université Laval, Quebec \\ Jean-Yves Duclos \\ Université Laval, Quebec, and Institut d'Anàlisi Economica (CSIC), Barcelona \\ Audrey Verdier-Chouchane \\ African Development Bank, Tunis
}

\begin{abstract}
This paper proposes a multidimensional procedure for jointly assessing the absolute and relative pro-poorness of growth. It is also a procedure for testing whether poverty comparisons can be made over classes of indices that incorporate both absolute and relative views of poverty. Besides being robust to whether pro-poor judgements should be absolute or relative, the procedure is also robust to choosing over a class of weights to aggregate the impact of growth on the poor as well as over ranges of absolute and relative poverty lines. The test is applied to distributional changes in five middle- and four lower-income African countries, countries that have witnessed different impacts of growth in the last two decades.
\end{abstract}

Special Issue

The Measurement of Inequality and Well-Being: New Perspectives

JEL D63, I32

Keywords Pro-poor growth; absolute poverty; relative poverty; stochastic dominance

Correspondence Jean-Yves Duclos, Département d'Économique and CIRPEE, Université Laval, Pavillon de Seve, G1V0A6 Quebec, Canada ; e-mail: jyves@ecn.ulaval.ca.

Citation Sami Bibi, Jean-Yves Duclos and Audrey Verdier-Chouchane (2012). Assessing Absolute and Relative Pro-poor Growth, with an Application to Selected African Countries. Economics: The Open-Access, OpenAssessment E-Journal, Vol. 6, 2012-7. http://dx.doi.org/10.5018/economics-ejournal.ja.2012-7 


\section{Introduction}

Assessing whether distributional changes are "pro-poor" has become increasingly important in the last decade-for early contributions, see inter alia Bourguignon (2004), Dollar and Kraay (2002), Eastwood and Lipton (2001), Ravallion (2001), IMF et al.(2000), and Collier and Dollar (2001)). Doing this requires fixing the concept of pro-poorness: this is usually related to the idea that the poor get "more" from growth than some predefined benchmark. An important issue is whether this benchmark should be absolute or relative. Another issue is whether pro-poor judgements should use distributional weights that vary across the poor. Yet one more important issue is where to draw the poverty line (in absolute or in relative terms).

In assessing whether distributional changes are pro-poor, caution is thus needed for several reasons.

First, the link made between growth and changes in poverty can be sensitive to the choice of poverty lines and poverty indices. For instance, even if the incomes of the poor always increased in line with average growth in the economy, the impact of growth on the headcount ratio (a popular choice among many possible poverty indices) would depend on the income density around the poverty line, and thus on the choice of that poverty line. Other poverty indices will almost always react quantitatively differently from the headcount following growth, and they may sometimes also move in a qualitatively opposite direction-for example, when growth decreases the incidence of poverty but increases its severity.

Second, the impact of growth on absolute poverty is often different from its impact on relative poverty and relative inequality. Indeed, although positive income growth usually increases the absolute incomes of the poor, it does not have a systematic effect on their relative shares in total income. This can have immediate repercussions on whether growth can be considered unambiguously to be pro-poor. This is because the two leading views on how to make judgements of pro-poorness differ radically as to whether growth should be expected to change the incomes of the poor by at least some absolute amount-for absolute pro-poor views - or by at least some proportional amount—for relative pro-poor views. 
For instance, the absolute pro-poor view will judge as equally pro-poor the following two changes in an income distribution: 1) the first one shows an increase of $\$ 1$ in the incomes of everyone; 2) the second one shows an increase of $\$ 1$ in the incomes of the poor and an increase of $\$ 10.000$ in the incomes of everyone else. This is because the absolute pro-poor view attaches no weight to the relative impact of growth, and that it also incorporates an absolute definition of the poverty line.

Conversely, the relative pro-poor view will judge as equally pro-poor two changes in an income distribution, a first one in which everyone sees his income fall by 50 percent, and a second one in which everyone sees his income increase by 50 percent. This is because the relative pro-poor view only considers the relative impact of growth. Both views are well illustrated in a collection of "onepagers” produced by UNDP (2009).

To assess whether growth is pro-poor, it has therefore often been the practice of the previous literature first to distinguish between absolute and relative propoorness, and then to focus on summary pro-poor measures with fixed poverty lines and with separate absolute and relative settings. Influential examples include Dollar and Kraay (2002), Kakwani et al. (2003), Kakwani and Pernia (2000), Klasen (2004), and Ravallion and Chen (2003); see also Araar et al. (2009) for a review.

This paper follows a different route by investigating how pro-poor judgements can be made robust to the choice of pro-poor evaluation functions and to the choice of poverty lines, in a joint absolute and relative setting. This in the spirit of Sen (1981)'s view that it may not be desirable to choose between the two settings, and that the joint use of the two settings may be useful to assess whether development is being pro-poor or not:

"Indeed, there is an irreducible core of absolute deprivation in our idea of poverty, which translates reports of starvation, malnutrition and visible hardship into a diagnosis of poverty without having to ascertain first the relative picture. Thus the approach of relative deprivation supplements rather than supplants the analysis of poverty in terms of absolute dispossession” (Sen 1981: 17).

We investigate jointly absolute and relative pro-poorness by considering classes of pro-poor evaluation functions that can show varying distribution sensitivity to the 
assessment of the impact of growth, be it in an absolute or in a relative setting. This is done in the spirit of the poverty dominance literature, and this also allows considering ranges of possible poverty frontiers within which to define the sets of the poor, absolutely and relatively speaking.

More generally, the methodological procedures introduced in this paper are also procedures for testing whether poverty comparisons can be made robustly over classes of indices that incorporate both absolute and relative views of poverty. Besides addressing robustness to whether pro-poor judgements should be absolute or relative, the procedures also enable to check for whether pro-poor judgements are robust to choosing over a class of weights to aggregate the impact of growth on the poor as well as over ranges of absolute and relative poverty lines.

The testing procedures are applied to the assessment of distributional changes in five middle- and four lower-income African countries, using data on household incomes (as opposed to aggregate income data, as captured for instance by GDP estimates). The results exemplify the significantly different impacts that growth has had over the last two decades in Africa.

The rest of the paper runs as follows. Section 2 formalizes this paper's assessment of the pro-poorness of growth, using both relative and absolute approaches and standards. Section 3 applies the techniques to relatively recent distributional changes in nine African countries. It also positions the results within the policy and economic environment in which these countries have recently evolved. Section 4 concludes by summarizing the main conclusions of the paper.

\section{Assessing Absolute and Relative Pro-Poorness}

We start Section 2.1 by drawing from Duclos et al. (2006) in order to make general poverty comparisons based on multidimensional indicators of welfare. Section 2.2 then describes how this general framework can be adapted to the important special case of comparing absolute and relative poverty using monetary indicators such as income or consumption. Section 2.3 provides a graphical discussion of the framework. 


\subsection{The General Setting}

Let a distribution of absolute $(a)$ and relative $(r)$ individual-level welfare indicators be given by $F^{j}(a, r)$ at time $j, j=A, B$. Absolute indicators of welfare will serve to assess whether growth has been absolutely pro-poor; relative indicators of welfare (namely, indicators of one's welfare relative to that of others) will serve to evaluate whether growth has been relatively pro-poor. These indicators can themselves be based on any variable (or combinations of variables) of interest, such as consumption, income, wealth, education or health, on which we would like to assess the impact of growth and distributional changes on poverty. Absolute indicators will be defined in the application section below by dollar values of consumption, and relative indicators will be given by those dollar values as a percentage of average consumption.

Then denote by:

$$
\lambda(a, r): \mathfrak{R}^{2} \rightarrow \mathfrak{R} \mid \frac{\partial \lambda(a, r)}{\partial a} \geq 0, \frac{\partial \lambda(a, r)}{\partial r} \geq 0
$$

a summary indicator of the overall degree of joint absolute and relative welfare of an individual with $(a, r)$. Note that the derivative conditions in (1) mean that both absolute and relative welfare can each contribute to increasing overall welfare.

For poverty measurement, we typically wish to focus on those with the greatest degree of overall deprivation. This can be done by drawing a frontier separating those with lower and greater welfare. We can think of this frontier as a series of points at which overall welfare is kept constant. This frontier is assumed to be defined implicitly by $\lambda(a, r)=0$. The set of those over whom we want to aggregate overall deprivation is then obtained formally as:

$$
\Lambda(\lambda)=\{(a, r) \mid(\lambda(a, r) \leq 0\}
$$

Consider Figure 1 with thresholds $z_{a}$ and $z_{r}$ in dimensions of indicators $a$ and $r$. Figure 1 allows comparing different views for identifying poor individuals in a multidimensional context; see for instance Bourguignon and Chakravarty (2003), Duclos et al. (2006) and Alkire and Foster (2009). $\lambda_{1}(a, r)$ gives an "intersection" view of joint deprivation: it considers someone to be overall deprived only if he is 
deprived in both of the dimensions $a$ and $r$, and therefore if he lies within the dotted rectangle of Figure 1 . All of those within that dashed rectangle will then be considered deprived. Since this measure of deprivation will have an important role to play later on, we will refer to it as an intersection headcount of joint deprivation, defined jointly over absolute and relative welfare as:

$$
H^{j}\left(z_{a}, z_{r}\right)=\int I\left(a \leq z_{a}\right) I\left(r \leq z_{r}\right) d F^{j}(a, r) .
$$

where $I(\bullet)$ is an indicator function that equals 1 if its argument is true and 0 otherwise, and $F^{j}(a, r)$ is the distribution function at time $j$ over $a$ and $r$. $H^{j}\left(z_{a}, z_{r}\right)$ is thus the proportion of $j$ 's total population that is deprived in both $a$ and $r$.

Figure 1: Deprivation in the space of absolute and relative welfare

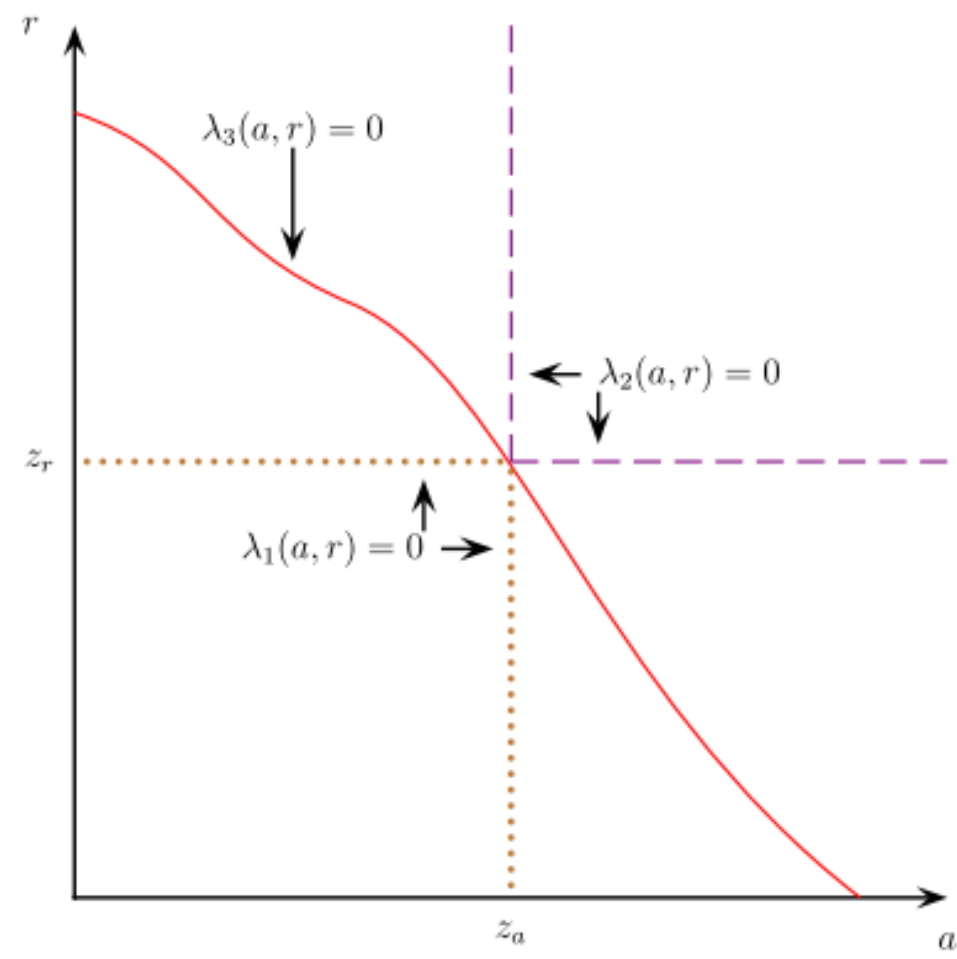


Other views and frontiers of joint deprivation can also be applied. $\lambda_{2}(a, r)$ (the L-shaped, dotted line) gives a "union" frontier: it considers someone to be overall deprived if he is deprived in either of the two dimensions, and therefore if he lies below or to the left of the dashed line. Finally, $\lambda_{3}(a, r)$ provides an intermediate approach. According to that approach, someone can be overall deprived even if $r$ $>z_{r}$, so long as his $a$ value is sufficiently low to lie to the left of $\lambda_{3}(a, r)=0$, and vice versa.

We are then interested in computing an aggregate index of overall deprivation based on the joint distribution of $a$ and $r$. Note that this aggregate index does not have to aggregate over the summary indicator $\lambda(a, r)$; it can aggregate over another indicator of individual deprivation, also function of of $a$ and $r$. We focus on classes of overall deprivation indices that are additive across individuals. An additive deprivation index for the distribution at time $j$ that combines the two dimensions of welfare of $a$ and $r$ is defined as:

$$
P^{j}(\pi, \lambda)=\iint_{\Lambda(\lambda)} \pi(a, r ; \lambda) d F^{j}(a, r)
$$

where $P^{j}(\pi, \lambda)$ is the aggregate index of poverty at time $j$, and $\pi(a, r ; \lambda)$ is the contribution (the "individual-level poverty") to aggregate deprivation of an individual with absolute and relative welfare given by $a$ and $r$. The double integral in (4) integrates over all those values of $a$ and $r$ that obey condition (2). Note that $P^{j}(\pi, \lambda)$ depends both on $\lambda$ and $\pi$. This is a source of concern since it is not easy to agree on who exactly should be deemed to be poor (the role of $\lambda$ ) and on how to quantify their degree of deprivation (the role of $\pi$ ).

We will say that the movement from time $A$ to time $B$ is pro-poor if and only if $P^{A}(\pi, \lambda) \geq P^{B}(\pi, \lambda)$. Again, whether the change will be deemed pro-poor will depend on the way in which $\lambda, \pi, a$ and $r$ are chosen. One of the main objectives of this paper is indeed to show how assessments of pro-poorness can be made robust to some of these choices.

To do this, let us for now assume that a choice of indicators $a$ and $r$ has been made. Assume first for simplicity that $\pi$ in (4) is left differentiable with respect to $a$ and $r$ and denote by $\pi^{a}$ and $\pi^{r}$ the first-order derivatives - which include the effect of $a$ and $r$ on $\lambda(a, r)$ - of $\pi(a, r ; \lambda(a, r))$ with respect to $a$ and $r$, and let $\pi^{a r}$ be the derivative of $\pi^{a}$ with respect to $r$. 
We can then define the following classes of joint absolute/relative deprivation indices:

$$
\Pi\left(\lambda^{+}\right)=\left\{\begin{array}{l|l}
P(\pi, \lambda) & \begin{array}{l}
\Lambda(\lambda) \subset \Lambda\left(\lambda^{+}\right) \\
\pi(a, r ; \lambda)=0, \text { whenever } \lambda(a, r)=0 \\
\pi^{a}(a, r ; \lambda) \leq 0 \text { and } \pi^{r}(a, r ; \lambda) \leq 0, \forall(a, r) \\
\pi^{a r}(a, r ; \lambda) \geq 0, \forall(a, r) .
\end{array}
\end{array}\right\}
$$

The first line of (5) says that an index $\mathrm{P}(\pi, \lambda)$ in $\Pi(\lambda+)$ can add up the deprivation of of any possible sets $\Lambda(\lambda)$ of deprived individuals so long as they are parts of a larger set $\Lambda(\lambda+)$. The set $\Lambda(\lambda+)$ is thus to be understood as the broadest set of deprived individuals that the class of indices $\Pi(\lambda+)$ can take into account.

The second line of (5) says that those with (a, r) just at the deprivation frontier $\lambda(\mathrm{a}, \mathrm{r})=0$ do not contribute to total deprivation in the population. Said differently, the measure $\pi(\mathrm{a}, \mathrm{r} ; \lambda)$ is continuous in $(\mathrm{a}, \mathrm{r})$ at $\lambda(\mathrm{a}, \mathrm{r})=0$.

The third line of (5) says that an increase in either a or $r$ decreases deprivation. An improvement in welfare, absolute of relative, this decreases deprivation.

Finally, the last line of (5) says that an increase in a increases $\pi \mathrm{r}(\mathrm{a}, \mathrm{r} ; \lambda)$ : the greater the value of a, the lower the fall in deprivation that is brought about by an increase in $r$. This also says that the types of deprivation are "substitutes".

Let $\Delta \mathrm{P}(\pi, \lambda)=\mathrm{PB}(\pi, \lambda)-\mathrm{PA}(\pi, \lambda)$ and $\Delta \mathrm{H}(\mathrm{za}, \mathrm{zr})=\mathrm{HB}(\mathrm{za}, \mathrm{zr})-\mathrm{HA}(\mathrm{za}$, $\mathrm{zr}$ ). The following equivalence can be shown (the proof follows from Duclos, Sahn, and Younger 2006): ments)

Proposition 1 (Joint dominance over absolute and relative deprivation judge-

$$
\begin{aligned}
& \Delta P(\pi, \lambda)<0, \forall P(\pi, \lambda) \in \Pi\left(\lambda^{+}\right) \\
& \operatorname{iff} \Delta H\left(z_{a}, z_{r}\right)<0, \forall\left(z_{a}, z_{r}\right) \in \Lambda\left(\lambda^{+}\right)
\end{aligned}
$$

Proposition 1 says that to be able to conclude that joint absolute/relative deprivation is lower in distribution $B$ than in distribution $A$ for all indices in $\Pi\left(\lambda^{+}\right)$, 
conomics: The Open-Access, Open-Assessment E-Journal

it is necessary and sufficient that the intersection headcount $H\left(z_{a}, z_{r}\right)$ be lower in $B$ for all of the possible intersection poverty lines $\left(z_{a}, z_{r}\right)$ in $\Lambda\left(\lambda^{+}\right)$.

\subsection{Absolute and Relative Deprivation in the Income Dimension}

The result of Proposition 1 shows how to make joint absolute and relative pro-poor judgements that are robust to broad classes of specifications of $\pi$ and $\lambda$. The only restrictions that need to be imposed on $\pi$ and $\lambda$ are given by (2) and (5).

This still leaves open the choice of the $a$ and $r$ indicators. The most popular ways to assess absolute and relative welfare and poverty/deprivation are based on the use of income (or consumption). This is also what we will do in the application section below. Denoting income as $y$, we therefore express $a$ and $r$ as functions $a^{j}(y)$ and $r^{j}(y)$. The superscripts $j$ express the possible dependence of these functions on the distribution $j$ in which the incomes are observed. $a^{j}(y)$ and $r^{j}(y)$ therefore stand for the absolute and relative welfare of someone with income $y$ in a distribution $j$. We then have:

$$
P^{j}(\pi, \lambda)=\int_{\Lambda(\lambda)} \pi\left(a^{j}(y), r^{j}(y) ; \lambda\right) d F^{j}(y) .
$$

In pursuing this route, it is useful to ensure that the aggregation procedure described in (7) incorporates both absolute and relative standards of income deprivation. A formal treatment of such standards is provided in Duclos (2009). It is sometimes argued that a change is good for the poor if it increases the poor's absolute living standards (see Ravallion and Chen 2003 for instance); this is the main justification for incorporating absolute welfare concerns in the pro-poor judgements. It is also sometimes posited that growth should be judged to be propoor only if it benefits more, or harms less, the poor than the non-poor (see Kakwani and Pernia 2000 for instance); this is the main motivation for incorporating relative welfare concerns in the pro-poor judgements.

Take the case of absolute welfare, again measured by $a^{j}(y)$. The following axiom circumscribes it.

Axiom $1 a^{j}(y)$ captures concerns for absolute welfare if and only if

$$
\int \pi\left(a^{j}(y), r^{j}(y) ; \lambda\right) d F^{j}(y)=\int \pi\left(a^{i}(y), r^{j}(y) ; \lambda\right) d F^{j}(y)
$$




\section{for all possible distributions $F^{i}(y)$ and $F^{j}(y)$.}

Axiom 1 says that pro-poor judgements should remain invariant to whether we use $a^{i}(y)$ or $a^{j}(y)$ to take into account concerns for absolute welfare in $P^{j}(\pi, \lambda)$. This is an invariance property that essentially forces the function $a^{j}(y)$ not to depend on $j$; said differently, we should have that $a(y)=a^{i}(y)=a^{j}(y)$. Given the general formulation of the function $\pi$, we can, without loss of generality, therefore just set $a(y)=y$.

Now take the case of relative welfare, which is captured by $r^{j}(y) \cdot r^{j}(y)$ will generally take into account the distribution of income $F^{j}(\cdot)$ when it comes to assess the relative welfare of someone with $y$ in $j$. That will also take into account the change in the distribution of income when we assess by how much the incomes of the poor must change to "catch up" with the change in the overall distribution of income. Let $F^{j, \gamma}(y)=F^{j}(\gamma y)$ and $r^{j, \gamma}(y)$ be defined relative to the distribution $F^{j, \gamma}(y)$. $F^{j, \gamma}(y)$ is thus obtained by scaling (dividing) the distribution of incomes in $j$ by $\gamma$.

Axiom $2 r^{j}(y)$ captures relative welfare concerns if and only if, for all $\gamma>0$,

$$
\int \pi\left(y, r^{j}(y) ; \lambda\right) d F^{j}(y)=\int \pi\left(\gamma y, r^{j, \gamma}(y) ; \lambda\right) d F^{j, \gamma}(y)
$$

for all possible distributions $F^{j}(y)$.

Axiom 2 assesses deprivation in two distributions, one with $j$ 's incomes, and one with $j$ 's incomes divided by $\gamma$. If absolute welfare is adjusted to be the same in the two distributions (by multiplying $y$ by $\gamma$ ), then Axiom 2 says that deprivation should be judged the same in the two distributions. Said differently, pro-poor judgements should remain invariant to whether we use $F^{j}(y)$ or $F^{j, \gamma}(y)$ for aggregating relative welfare. Scaling incomes up or down should not affect relative welfare. This is an invariance property that essentially also forces the function $r^{j}(y)$ to be homogeneous of degree 0 in $y$ and in the distribution of incomes $F^{j}(\cdot)$.

There are many ways for enforcing this homogeneity property. One of the simplest ways is to normalize incomes in $r^{j}(y)$ by a summary statistic of the income distribution $j$ that is homogeneous of degree 1 in the income distribution. The mean is an obvious and common candidate to do this in the context of relative 
poverty comparisons - though other distribution-dependent statistics such as the median or the mode could also be applied. This is what we use in this paper's application in Section 3, in accordance with most of the existing literature on assessing relative pro-poorness. Letting the mean of distribution $j$ be $\mu^{j}=$ $\int y d F^{j}(y)$, this is formally equivalent to imposing the following axiom.

Axiom $3 r^{j}(y)$ is defined as mean-normalized relative welfare if and only if, for all $\gamma>0$,

$\int \pi\left(y, r^{j}(y) ; \lambda\right) d F^{j}(y)=\int \pi\left(\mu^{j} y, r(y) ; \lambda\right) d F^{j, \mu^{j}}(y)$

for all possible distributions $F^{j}(y)$, and where $r(y)$ is independent of the distribution $F^{j}(\cdot)$.

Given the general formulation of the function $\pi$, we can then set $r^{j}(y)=y / \mu^{j}$ without loss of generality. Note that this framework is general enough to accommodate negative as well as positive income growth. This leads to joint absolute/relative indices of the form:

$$
P^{j}(\pi, \lambda)=\int_{\Lambda(\lambda)} \pi\left(y, y / \mu^{j} ; \lambda\right) d F^{j}(y)
$$

\subsection{Comparing Absolute and Relative Income Deprivation}

Using (3), (8) and Proposition 1, we therefore have that $\Delta P(\pi, \lambda)<0$, $\forall P(\pi, \lambda) \in \Pi\left(\lambda^{+}\right)$(where the $P$ are absolute/relative income deprivation indices) if and only if $\Delta H_{*}\left(z_{a}, z_{r}\right)<0, \forall\left(z_{a}, z_{r}\right) \in \Lambda\left(\lambda^{+}\right)$, where

$$
H_{*}^{j}\left(z_{a}, z_{r}\right)=\int I\left(y \leq z_{a}\right) I\left(y / \mu^{j} \leq z_{r}\right) d F^{j}(y)
$$

The fact that both $a$ and $r$ depend solely on $y$ leads to a simplification of the general testing procedure described in Proposition 1. To see this, consider Figure 2. Absolute income is shown on the horizontal axis $(y)$, and relative income is shown on the vertical one $(y / \mu)$. The lines $j=A$ and $j=B$ show where incomes lie 
for the two distributions. The slope of each line is given by $1 / \mu^{j}$. Testing for joint absolute and relative deprivation amounts to comparing the proportion of individuals lying within a rectangle that starts at $(0,0)$ and that ends at $\left(Z_{a}, Z_{r}\right)$.

First assume that mean income has increased in moving from $A$ to $B$, as is also implicitly assumed in Figure 2. Individuals are concentrated on the lines $A$ and $B$. Marginal dominance can be checked by comparing $F^{j, 1}\left(z_{a}\right)$ at different $z_{a}$ for checking absolute welfare dominance, and by comparing $F^{j, \mu j}\left(z_{r}\right)$ at various $z_{r}$ for checking relative welfare dominance. This leads to a few interesting relationships (again, for the case in which $\mu^{A}<\mu^{B}$ ).

1. First assume, as in Figure 2, that $F^{B, \mu B}\left(z_{r}\right) \leq F^{A, \mu A}\left(z_{r}\right)$ for $\left.\left.z_{r} \in\right] 0, z_{r}^{0}\right]$. This implies that $F^{B}\left(\mu^{B} z_{r}^{0}\right)=F^{B}\left(z_{a}^{0}\right) \geq F^{A}\left(\mu^{A} z_{r}^{0}\right) . F^{B}\left(z_{a}^{0}\right)$ on Figure 2 is the proportion of individuals in population $B$ that are lying on segment $o d$. $F^{A}\left(z_{a}^{0}\right)$ is the proportion of individuals in population $A$ that are lying on segment oc. Also assume that $F^{B, \mu B}\left(z_{r}\right)>F^{A, \mu A}\left(z_{r}\right)$ for $z_{r}>z_{r}^{0}$. Then, it must be that $F^{B}\left(z_{a}\right) \leq F^{A}\left(z_{a}\right)$ for $\left.z_{a} C\right] 0, \mu^{A} z_{r}^{0}$, where $\mu^{A} z_{r}^{0}{ }_{r}=z^{0}{ }_{a}$ in Figure 2. It must indeed also be that $\Delta H_{*}\left(z_{a}, z_{r}\right)<0$ for all $\left(z_{a}, z_{r}\right)$ in $] 0$, $\left.\infty[\otimes] 0, z_{r}^{0}\right]$. Therefore, if a distribution $B$ with a higher mean than $A$ relatively dominates $A$, then it must also be that $B$ dominates $A$ over some $\Pi(\lambda)$. This area $\Lambda(\lambda)$ is the dashed area on Figure 2.

2. Suppose in addition that $F^{B}\left(z_{a}\right) \leq F^{A}\left(z_{a}\right)$ for $\left.z_{a} C\right] 0, z_{a}^{1}$, and that $F^{B}(z$ $\left.{ }_{a}\right)>F^{A}\left(z_{a}\right)$ for $z_{a}>z_{a}^{1}$. By the above, it must be that $z_{a}^{0} \leq z_{a}^{1}$. It must then also be that $\Delta H_{*}\left(z_{a}, z_{r}\right)<0$ for all $\left(z_{a}, z_{r}\right)$ in $\left.\left.\left.] 0, z_{a}^{0}\right] \otimes\right] 0, \infty\right]$. This area $\Lambda(\lambda)$ is the dotted area on Figure 2.

3. Under the above setting, there also exists an area between $z^{0}{ }_{a}$ and $z^{1}{ }_{a}$ where $\Delta H_{*}\left(z_{a}, z_{r}\right)<0$. This is the shaded area on Figure 2 that is bounded to the right by the line that links point $d$ to point $e$.

4. To sum up, if $\mu^{A}<\mu^{B}$ and if for some $z_{r}^{0}$ we have that $F^{B, \mu B}\left(z_{r}\right) \leq F^{A, \mu A}(z$ r) for $\left.z_{r} \in\right] 0, z_{r}^{0}$, we also have that $\Delta H_{*}\left(z_{a}, z_{r}\right)<0$, over the area $\Lambda\left(\lambda^{+}\right)$ shown jointly by the dashed, the dotted and the shaded areas in Figure 2. This also says that all of the indices that are members of the absolute/relative class $\Pi\left(\lambda^{+}\right)$will necessarily declare a movement from $A$ to $B$ to be pro-poor. 
Figure 2: Joint absolute and relative pro-poor growth

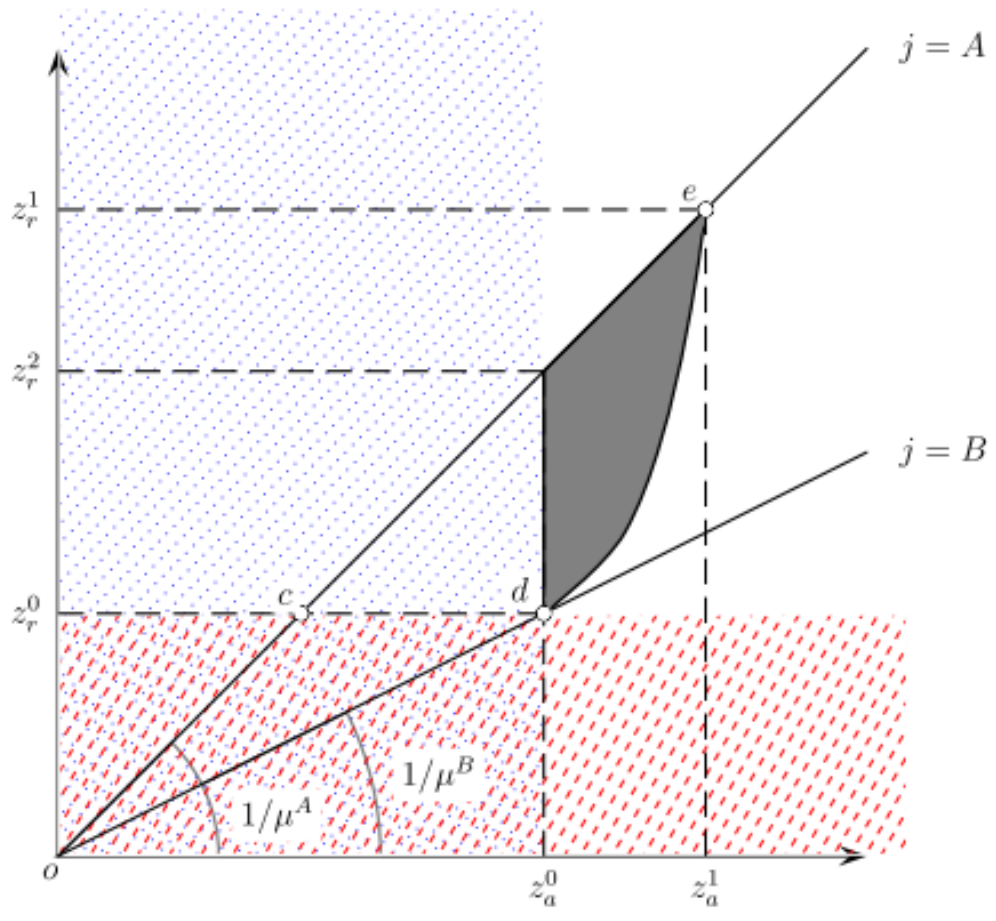

A similar and symmetric reasoning applies to the case in which the movement from $A$ to $B$ generates a fall in average income, that is, if $\mu^{A}>\mu^{B}$. If a distribution $A$ with a higher mean than $B$ relatively dominates $B$, then it must also be that $A$ dominates $B$ over some absolute/relative poverty indices $\Pi\left(\lambda^{+}\right)$. This also says that all of the indices that are members of the absolute/relative class $\Pi\left(\lambda^{+}\right)$will declare the movement from $A$ to $B$ to be anti-poor.

Note finally that the class $\Pi\left(\lambda^{+}\right)$of pro-poor indices includes multidimensional indices that can be of the intersection, union or intermediate types. All that is required is that those indices be defined within the area $\Lambda\left(\lambda^{+}\right)$. This is despite the fact that, to test for robustness of pro-poor assessments over the class $\Pi\left(\lambda^{+}\right)$, intersection indices of the type (9) must be used. 


\section{Application}

\subsection{Data and Estimation Procedures}

We illustrate the application of the method introduced above by applying it to relatively recent distributional changes in nine African countries. This is of interest in itself given the considerable importance that African development has had in international policy circles. The nine countries are the Central African Republic (CAR), Egypt, Ethiopia, Malawi, Mauritania, Mauritius, Morocco, South Africa and Tunisia; the covered periods range from 1993 to 2007. As will become clear below, these countries have experienced sometimes quite different patterns of growth and poverty changes over that period. They had been selected in part because of these different growth experiences and because they cover a wide geographical range.

The household data on Mauritius are obtained from the Central Statistics Office's seventh and eighth Household Budget Surveys (2001/2002 and 2005/2006) — see http://www.gov.mu/portal/site/. The household data on South Africa have been collected into the Surveys on the income and expenditure of households (1995/1996 and 2005/2006) by Statistics South Africa-see http://www.statssa.gov for more information.

Except for Mauritius and South Africa, for which we had access to the household level data, the welfare distributions are obtained by reconstructing individual expenditure observations from information on cumulative expenditure shares-namely, Lorenz curve coordinates. The procedure followed to reconstruct individual expenditure observations is that suggested by Shorrocks and Wan (2008). In contrast to several alternative methods, this procedure ensures that the Lorenz curve ordinates of the reconstructed samples match exactly those that are initially used. ${ }^{1}$

Most of the cumulative expenditure shares are available on the World Bank's PovCalNet web site (http://iresearch.worldbank.org/PovcalNet/jsp). Lorenz curve ordinates have also been obtained from other sources: Ministère des Affaires Economiques et du Développement (2006) for the 2004 Mauritanian expenditure

1 For this purpose, we have used the latest version of the Distributive Analysis Stata Package (DASP) of Araar and Duclos (2007), which readily applies this procedure. 
distribution, and Institut National de la Statistique (2007) for 2005 Tunisian cumulative expenditure shares.

To compare poverty across time and countries, we need measurement units that are comparable across time and space. This is readily provided by the PovCalNet data. The per capita expenditure data obtained from sources other than PovcalNet are transformed into 2005 prices using the consumer price indices published by the national authorities of each country. These expenditures are then converted into 2005 US dollars using the 2005 purchasing power parities (PPP) found in PovcalNet for Mauritania and those 2005 PPP found in World Bank (2008) for Mauritius, South Africa and Tunisia. PPP are commonly used for comparing absolute poverty and social welfare; such cross-country comparisons should, however, be interpreted with caution since they can be sensitive to marginal changes in the PPP. Relative poverty comparisons are not, however, sensitive to changes in national PPP. ${ }^{2}$ Note also that differences in the construction of consumption aggregates and in adjustments for differences in spatial prices further make comparisons across the countries difficult.

Standard errors and confidence intervals for Mauritius' and South Africa's poverty estimates are computed taking account sampling weights and sampling design information. It is unfortunately not possible to compute standard errors and confidence intervals with the same rigor for the poverty estimates of those countries for which we do not have access to the micro data and for which we must instead reconstruct individual expenditure observations. The most important reason for this is that the Lorenz curves estimates used for those countries do not tell us anything about the sampling design effect of the surveys initially used to compute those Lorenz curves estimates.

To provide a rough idea of the sampling variability of the poverty estimates for those other seven countries, we nevertheless compute and provide standard errors on poverty estimates assuming that these estimates come from a survey of 1000 independently and identically drawn individual expenditure observations. This number contrasts with the true sample size of the surveys initially used to compute the Lorenz curves estimates, a sample size that is usually between 10,000 to 12,000 observations. All of these initial surveys are, however, made of clusters of

2 See for example Chen et al. (1994) for a discussion of the use of PPP for international comparisons of poverty. 
around 10 to 12 observations each. Such clustering has the well-known effect of increasing substantially the sampling variability of the poverty estimates computed from the reconstructed data. The assumption of a sample size of only 1000 observations (instead of 10,000 to 12,000) is made to allow roughly for this clustering effect. Our checks of the validity of this procedure to compute standard errors (based on the use of those two micro data to which we have access) suggest that the standard errors thus obtained are not far from (and slightly larger than) those that would be computed by properly using the true underlying micro data and sampling design information.

\subsection{Descriptive Statistics}

Table 1 provides descriptive statistics on average daily per capita expenditures across the countries, the incidence of absolute poverty $\left(H_{*}\left(z_{a}, \infty\right)\right)$ for a poverty line $z$ a set at " 2 dollars a day" for those countries whose mean per capita expenditure was above 2 dollars and " 1 dollar a day" for the other three countries (CAR, Ethiopia and Malawi), the incidence of relative poverty $\left(H_{*}\left(\infty, z_{r}\right)\right.$ ) for a poverty line $z_{r}$ set at half of mean expenditure, and the Gini index.

Table 1 shows that the mean per capita expenditure of the second group (CAR, Ethiopia and Malawi) is not far from the conventional " 1 dollar a day" poverty line. This naturally leads to high absolute poverty rates as compared with the relative poverty rates of these countries. For example, Malawi had an absolute poverty rate of 61.2 percent and a relative poverty rate of 25.4 percent in 2004 . With the notable exceptions of Egypt and Mauritania, the other countries (including South Africa) show levels of absolute poverty rates by far lower than the relative incidence of poverty.

One may also remark that all countries have witnessed a fall in absolute poverty, even if it is not quite significant in Mauritius and South Africa. Conversely, these latter two countries plus Egypt have experienced a significant increase in their relative poverty rates.

The second group of countries (CAR, Ethiopia and Malawi) has witnessed the most important decline in both absolute and relative poverty. The results are shown in Figures A1, A3 and A5, and can be seen to be statistically significant. CAR has experienced a reduction of 25.8 points of percentage in the incidence of absolute poverty between 1993 and 2003, and a decline of 19.2 points in the 
incidence of relative poverty. All other countries with the exception of Tunisia have recorded an increase in relative poverty. No country has registered an increase in both absolute and relative poverty.

Table 1: Descriptive statistics

\begin{tabular}{|c|c|c|c|c|c|c|c|c|c|}
\hline & \multicolumn{3}{|c|}{ CAR } & \multicolumn{3}{|c|}{ Ethiopia } & \multicolumn{3}{|c|}{ Malawi } \\
\hline & 1993 & 2003 & $\Delta$ & 1995 & 2005 & $\Delta$ & 1997 & 2004 & $\Delta$ \\
\hline $\begin{array}{c}\text { Mean p.c } \\
\text { expenditure }\end{array}$ & $\begin{array}{c}0.84 \\
(0.07)\end{array}$ & $\begin{array}{c}1.4 \\
(0.06)\end{array}$ & $\begin{array}{c}0.55 \\
(0.02)\end{array}$ & $\begin{array}{c}1.51 \\
(0.09)\end{array}$ & $\begin{array}{c}1.71 \\
(0.06)\end{array}$ & $\begin{array}{c}0.20 \\
(0.04)\end{array}$ & $\begin{array}{c}0.98 \\
(0.08)\end{array}$ & $\begin{array}{c}1.14 \\
(0.06)\end{array}$ & $\begin{array}{c}0.15 \\
(0.03)\end{array}$ \\
\hline $\begin{array}{c}H_{*}\left(\mathrm{z}_{a}, \infty\right) \\
\$ 1 \text { a day }\end{array}$ & $\begin{array}{l}76.8 \\
(1.9) \\
\end{array}$ & $\begin{array}{l}51.0 \\
(2.2) \\
\end{array}$ & $\begin{array}{l}-25.8 \\
(1.96) \\
\end{array}$ & $\begin{array}{l}43.6 \\
(2.2) \\
\end{array}$ & $\begin{array}{l}21.4 \\
(1.8) \\
\end{array}$ & $\begin{array}{l}-22.2 \\
(1.9) \\
\end{array}$ & $\begin{array}{l}75.4 \\
(1.9) \\
\end{array}$ & $\begin{array}{l}61.2 \\
(2.2) \\
\end{array}$ & $\begin{array}{l}-14.2 \\
(1.6) \\
\end{array}$ \\
\hline $\begin{array}{c}H_{*}\left(\infty, z_{r}\right) \\
z_{r}=0.5 \mu\end{array}$ & $\begin{array}{c}52.4 \\
(2.94) \\
\end{array}$ & $\begin{array}{l}33.2 \\
(2.2) \\
\end{array}$ & $\begin{array}{l}-19.2 \\
(2.03)\end{array}$ & $\begin{array}{l}24.4 \\
(3.3) \\
\end{array}$ & $\begin{array}{l}11.6 \\
(2.8) \\
\end{array}$ & $\begin{array}{l}-12.8 \\
(2.2)\end{array}$ & $\begin{array}{l}39.2 \\
(4.3) \\
\end{array}$ & $\begin{array}{l}25.4 \\
(2.6) \\
\end{array}$ & $\begin{array}{l}-13.8 \\
(2.5) \\
\end{array}$ \\
\hline Gini Index & $\begin{array}{c}61.6 \\
(2.65) \\
\end{array}$ & $\begin{array}{l}43.6 \\
(1.8) \\
\end{array}$ & $\begin{array}{c}-18 \\
(1.03) \\
\end{array}$ & $\begin{array}{l}39.9 \\
(3.0) \\
\end{array}$ & $\begin{array}{l}29.7 \\
(1.8) \\
\end{array}$ & $\begin{array}{l}-10.2 \\
(1.3) \\
\end{array}$ & $\begin{array}{c}50.2 \\
(3.51) \\
\end{array}$ & $\begin{array}{l}39.0 \\
(2.3) \\
\end{array}$ & $\begin{array}{l}-11.2 \\
(1.31)\end{array}$ \\
\hline \multirow[t]{3}{*}{$\begin{array}{c}\text { Number of } \\
\text { observations }\end{array}$} & 500 & 500 & & 500 & 500 & & 500 & 500 & \\
\hline & \multicolumn{3}{|c|}{ Egypt } & \multicolumn{3}{|c|}{ Mauritania } & \multicolumn{3}{|c|}{ Mauritius } \\
\hline & 1995 & 2004 & $\Delta$ & 1995 & 2004 & $\Delta$ & 2002 & 2007 & $\Delta$ \\
\hline $\begin{array}{c}\text { Mean p.c } \\
\text { expenditure }\end{array}$ & $\begin{array}{l}3.26 \\
(0.1) \\
\end{array}$ & $\begin{array}{c}3.75 \\
(0.12) \\
\end{array}$ & $\begin{array}{c}0.49 \\
(0.03)\end{array}$ & $\begin{array}{l}2.62 \\
(0.1) \\
\end{array}$ & $\begin{array}{l}3.62 \\
(0.2) \\
\end{array}$ & $\begin{array}{c}1 \\
(0.08)\end{array}$ & $\begin{array}{c}8.7 \\
(0.1) \\
\end{array}$ & $\begin{array}{l}9.66 \\
(0.1) \\
\end{array}$ & $\begin{array}{c}0.96 \\
(.)\end{array}$ \\
\hline $\begin{array}{c}H_{*}\left(z_{a}, \infty\right) \\
\$ 2 \text { a day }\end{array}$ & $\begin{array}{l}25.0 \\
(1.9)\end{array}$ & $\begin{array}{l}17.8 \\
(1.7)\end{array}$ & $\begin{array}{l}-7.2 \\
(1.2)\end{array}$ & $\begin{array}{l}48.6 \\
(2.2) \\
\end{array}$ & $\begin{array}{l}30.6 \\
(2.1) \\
\end{array}$ & $\begin{array}{c}-18 \\
(1.7)\end{array}$ & $\begin{array}{c}1.17 \\
(0.15)\end{array}$ & $\begin{array}{c}0.9 \\
(0.15) \\
\end{array}$ & $\begin{array}{l}-0.27 \\
(0.22)\end{array}$ \\
\hline $\begin{array}{c}H_{*}\left(\infty, z_{r}\right) \\
z_{r}=0.5 \mu\end{array}$ & $\begin{array}{l}11.2 \\
(1.6)\end{array}$ & $\begin{array}{l}14.0 \\
(1.8)\end{array}$ & $\begin{array}{c}2.8 \\
(0.7) \\
\end{array}$ & $\begin{array}{l}24.4 \\
(1.8) \\
\end{array}$ & $\begin{array}{l}24.4 \\
(2.4) \\
\end{array}$ & $\begin{array}{c}0.0 \\
(0.8) \\
\end{array}$ & $\begin{array}{l}17.8 \\
(0.6) \\
\end{array}$ & $\begin{array}{l}20.5 \\
(0.6) \\
\end{array}$ & $\begin{array}{l}2.67 \\
(0.9)\end{array}$ \\
\hline Gini Index & $\begin{array}{l}30.0 \\
(1.2) \\
\end{array}$ & $\begin{array}{l}32.0 \\
(1.4) \\
\end{array}$ & $\begin{array}{c}2.0 \\
(0.1) \\
\end{array}$ & $\begin{array}{l}37.3 \\
(1.3) \\
\end{array}$ & $\begin{array}{l}39.3 \\
(2.0)\end{array}$ & $\begin{array}{c}2 \\
(0.8) \\
\end{array}$ & $\begin{array}{c}34 \\
(0.5) \\
\end{array}$ & $\begin{array}{l}35.6 \\
(0.5)\end{array}$ & $\begin{array}{l}1.67 \\
(0.7) \\
\end{array}$ \\
\hline $\begin{array}{c}\text { Number of } \\
\text { observations }\end{array}$ & 500 & 500 & & 500 & 500 & & 6710 & 6720 & \\
\hline
\end{tabular}


conomics: The Open-Access, Open-Assessment E-Journal

Table 1 continued

\begin{tabular}{|c|c|c|c|c|c|c|c|c|c|}
\hline & \multicolumn{3}{|c|}{ Morocco } & \multicolumn{3}{c|}{ South Africa } & \multicolumn{3}{c|}{ Tunisia } \\
\hline & 1998 & 2007 & $\Delta$ & 1995 & 2005 & $\Delta$ & 1995 & 2005 & $\Delta$ \\
\hline Mean p.c & 4.33 & 5.38 & 1.05 & 8.67 & 10.8 & 2.1 & 5.14 & 7.26 & 2.12 \\
expenditure & $(0.2)$ & $(0.2)$ & $(0.06)$ & $(0.12)$ & $(0.23)$ & $()$. & $(0.2)$ & $(0.3)$ & $(0.1)$ \\
\hline$H_{*}\left(z_{a}, \infty\right)$ & 22.6 & 13.0 & -9.6 & 26.5 & 24.6 & -1.97 & 19.6 & 7.8 & -11.8 \\
$\$ 2$ a day & $(1.9)$ & $(1.5)$ & $(1.3)$ & $(1.3)$ & $(0.5)$ & $(1.4)$ & $(1.8)$ & $(1.2)$ & $(1.4)$ \\
\hline$H_{*}\left(\infty, z_{r}\right)$ & 27.0 & 27.2 & 0.2 & 55.0 & 64.0 & 9.0 & 30.6 & 29.2 & -1.4 \\
$Z_{r}=0.5 \mu$ & $(2.1)$ & $(2.3)$ & $(0.3)$ & $(0.76)$ & $(0.6)$ & $(0.97)$ & $(2.0)$ & $(2.1)$ & $(0.5)$ \\
\hline Gini Index & 39.4 & 40.5 & 1.1 & 61.5 & 67.3 & 5.8 & 41.6 & 41.3 & -0.3 \\
& $(1.5)$ & $(1.6)$ & $(0.1)$ & $(0.6)$ & $(0.5)$ & $(0.7)$ & $(1.5)$ & $(1.6)$ & $(0.1)$ \\
\hline Number of & 500 & 500 & & 29582 & 21144 & & 500 & 500 & \\
observations & & & & & & & & & \\
\hline
\end{tabular}

N.B. $H_{*}\left(\mathrm{z}_{a}, \infty\right)$ has been set at "\$2 a day" rate for countries whose mean per capita expenditure was above $\$ 2$ and " $\$ 1$ a day" rate for other countries (CAR, Ethiopia and Malawi). Standard errors appear within the parentheses.

These results prevent conventional first-order relative pro-poorness in Egypt, Mauritania, Mauritius, Morocco and South Africa because although these countries have experienced a decrease in their absolute poverty rates, their relative poverty rates have risen. Since a fall in the relative poverty rates is necessary for joint absolute and relative pro-poor dominance, the fact that relative poverty rates have increased also prevents bidimensional pro-poorness over $\Lambda\left(\lambda^{+}\right)$. This is visible from the univariate stochastic dominance tests of Figure A7 for Egypt, Figure A9 for Mauritania, Figure A11 for Mauritius, Figure A13 for Morocco and Figure A15 for South Africa. On the left-hand side of each of these figures, absolute poverty incidence $H^{j}\left(z_{a}, \infty\right)$ for country $j$ at each of the two time periods is drawn at the top for different $z_{a}$, while absolute poverty differences $\Delta H\left(z_{a}\right)$ are plotted at the bottom for the same range of $z_{a}$ (along with 95 percent confidence intervals). On the right-hand side, the relative poverty headcount, $H^{j}\left(\infty, z_{r}\right)$, is displayed at the top for different $z_{r}$ starting from 0 to 100 or 150 percent of mean per capita expenditure, $\mu^{j}$, whereas relative poverty differences, $\Delta H^{j}\left(\mathrm{z}_{a}\right)$, are depicted at the bottom. 


\subsection{Joint Absolute and Relative Pro-Poorness}

The results of the bivariate stochastic dominance tests formally described in Proposition 1 are shown in Figure A2 for CAR, Figure A4 for Ethiopia, Figure A6 for Malawi, Figure A8 for Egypt, Figure A10 for Mauritania, Figure A12 for Mauritius, Figure A14 for Morocco, Figure A16 for South Africa and Figure A18 for Tunisia. The front axis shows the range of absolute poverty lines $\left(z_{a}\right)$; the right axis shows the range of relative poverty lines $\left(z_{r}\right)$; and the vertical axis shows the difference in the joint incidence of absolute and relative deprivation $\left(\Delta H_{*}\left(\mathrm{z}_{a}, \mathrm{Z}_{r}\right)\right)$ at the points defined in the $\left(y, y / \mu^{j}\right)$ domain. Note that the unidimensional graphs discussed above are in fact the lateral views of the bidimensional graphs discussed in this section.

If $\Delta H_{*}\left(z_{a}, z_{r}\right)<0, \forall\left(z_{a}, z_{r}\right) \in \Lambda\left(\lambda^{+}\right)$, then economic growth has been unambiguously pro-poor, in the sense that the change will be deemed pro-poor for any choice of poverty indices and poverty frontiers in the class $\Pi\left(\lambda^{+}\right)$.

On the whole, two sets of countries strike out of the figures. ${ }^{3}$ The first set includes countries that have witnessed a robust fall in both absolute and relative poverty such as CAR, Ethiopia, Malawi, Mauritania and Tunisia. The remaining countries have witnessed a fall in one of the dimensions of deprivation and a rise in the other (Egypt, Mauritius, Morocco, and South Africa).

\subsubsection{Pro-poor Growth Experiences}

In the Central African Republic, Ethiopia, and Malawi, the tests are conducted for an upper $z_{a}$ equal to 5 dollars a day and an upper $z_{r}$ equal to 100 percent of $\mu^{j}$. Interestingly enough, these three low-income countries have experienced a robust decline both in absolute and in relative poverty. As a result, we can confidently conclude that their growth pattern has led to increasing incomes of the poor and reducing income inequality. The case of Mauritania and Tunisia is more ambiguous as absolute poverty and relative poverty have followed slightly different patterns.

\footnotetext{
${ }^{3}$ A third set of countries could regroup countries that have experienced a rise in both absolute and relative deprivation. These were the cases of Turkey over 1994-2005 and Yemen over 1998-2005 in Bibi et al. (2010).
} 
The left-hand side of Figure A17 for Tunisia shows that $\Delta H_{*}\left(\mathrm{z}_{a}, \infty\right)$ lies nowhere above zero (i.e., for $z_{a}<5$ ). Further, for any $z_{a}>1$, the negative values of $\Delta H_{*}\left(z_{a}, \infty\right)$ are statistically different from zero at the 5 percent level. The economic growth experienced by Tunisia between 1995 and 2005 has thus unambiguously decreased its level of absolute poverty. Said differently, there is first-order absolute poverty dominance for Tunisia of 2005 over $1995 .{ }^{4}$ Figure A9 shows that Mauritania has experienced a similar statistically significant fall in absolute poverty.

However, the right-hand side of Figure A9 for Mauritania and of Figure A17 for Tunisia show that $\Delta H_{*}\left(\infty, z_{r}\right)$ is not statistically negative for many of the $z_{r} C$ $[0,1]$. This means that it is not possible to infer statistically relative poverty dominance over all of that range of $z_{r}$. If we restrict the range of $z_{r}$ to $[0,0.8]$ for Tunisia and [0, 0.4] for Mauritania, and we ignore sampling variability, then we can conclude that economic growth has unambiguously decreased relative poverty in Tunisia and Mauritania.

Ignoring sampling variability, the presence of dominance both in the absolute and in the relative dimensions of welfare leads to joint pro-poor dominance in Tunisia as Figure A18 shows: $\Delta H_{*}\left(z_{a}, z_{r}\right)$ is either nil or negative but is never positive for any couple of $\left(z_{a}, z_{r}\right)$ in $[0,5] \otimes[0,0.8]$. A similar finding applies to Mauritania but within a narrower range of $z_{r}$. Figure A4 shows indeed that there is bivariate pro-poor dominance in Mauritania for any $\left(z_{a}, z_{r}\right)$ in $[0,5] \otimes[0,0.4]$.

Putting it differently, the growth pattern in CAR, Ethiopia, Malawi, Mauritania and Tunisia, has mostly led to a two-edged impact on poverty: increased incomes for the poor, and increased shares of the poor in total income. This has generated a lower degree of joint absolute/relative deprivation as measured by any index within $\Pi\left(\lambda^{+}\right)$.

\subsubsection{Inconclusive Effects of Growth on poverty}

The left-hand side of Figure A7 for Egypt, Figure A11 for Mauritius, and Figure A13 for Morocco clearly shows that $\Delta H_{*}\left(z_{a}, \infty\right)$ lies nowhere above zero (i.e., for $\left.z_{a}<5\right)$. Further, for several $z_{a}<5, \Delta H_{*}\left(z_{a}, \infty\right)$ is negative with values that are

\footnotetext{
${ }^{4}$ Poverty and inequality were, however, on the rise in Tunisia during the first half of the 1990s. More details can be found in Bibi and Nabli (2009).
} 
statistically negative at the 5 percent level. Economic growth experienced by these countries during the last decade or so has therefore tended to decrease absolute poverty. However, the right-hand side of these same figures shows that $\Delta H_{*}\left(\infty, z_{r}\right)$ is either nil or (often) statistically greater than 0 for values of $z_{r}$ within $[0,1]$. This indicates that we cannot conclude that the latter period dominates the earlier one in terms of relative poverty. South Africa shows a somewhat dissimilar pattern of economic growth. Absolute poverty has robustly decreased but for a narrow range of $z_{a}$ while relative poverty has unambiguously increased, as Figure A15 shows.

The absence of first-order dominance in the relative dimension of welfare rules out bivariate pro-poor dominance as Figure A8 for Egypt, Figure A12 for Mauritius Figure A14 for Morocco, and Figure A16 for South Africa show. $\Delta H_{*}(\mathrm{z}$ $\left.{ }_{a}, z_{r}\right)$ shows both positive and negative values, depending on the choice of $\left(z_{a}, z_{r}\right)$. There can therefore be no robust pro-poor judgment of the evolution of joint absolute and relative deprivation in these four countries, even if we ignore sampling variability.

\subsection{Discussion}

The above findings suggest that the different performances in terms of poverty reduction are country-specific and can also depend on the covered period. For example, the poverty analysis conducted by the African Development Bank (2010) in Morocco over 1990-1998 shows that the country experienced an absolute antipoor growth. The same analysis conducted here over 1998-2007 reveals that Morocco has experienced an absolute pro-poor growth. The analysis over the entire period would therefore be different from the one presented in this paper.

The methodology also allows for a consistent joint investigation of absolute and relative pro-poorness, a feature not found in earlier papers. It also avoids the debate on the choice of poverty lines and poverty indices, which can lead to conflicting results and make assessments and comparisons difficult. The paper's methodology may hence result in a definite and robust positive or negative response to whether growth has been pro-poor in a specific country. But it can, however, also lead to an inconclusive response. Nonetheless, even when the joint analysis is not conclusive, the use of graphs can provide useful guidance on the country-specific contexts of the impact of growth on absolute and relative poverty. 
As an example, Egypt has experienced a joint poverty increase up to certain coordinates on the axes, a mix picture thereafter, and then a joint decrease. As another example, Tunisia has seen a reduction in absolute and relative poverty most strikingly among the less poor of the poor. This is different from the information provided by the graphs of CAR or Malawi. These latter clearly show that extreme poverty has been more particularly reduced than in Egypt and Tunisia. A comparison between CAR (Figure A2) and Ethiopia (Figure A4) also provides a sense of the relative degree of pro-poorness in these two countries; Ethiopia has experienced a more moderate reduction in poverty relative to CAR.

The results are further suggestive of the importance and the effect of political will for poverty reduction. Most of the country analyses cover the period 19952005, a period during which the MDGs (Millennium Development Goals) have been put in place with an explicit objective of halving extreme poverty by 2015. In accordance with this, all of the African countries considered here have experienced a decrease in absolute poverty. However, although all low-income countries (CAR, Ethiopia, Malawi and Mauritania) have also seen a reduction in relative poverty, middle-income countries, with the exception of Tunisia, have not done so.

As a matter of fact, where poverty reduction has constituted a more official policy challenge. ${ }^{5}$ countries have tended to see a reduction in both absolute and relative poverty. Conversely, Egypt, Mauritius, Morocco and South Africa have witnessed an increase (or have not witnessed a fall) in inequality. It would perhaps seem natural and fair to say that poverty reduction strategies have not featured as prominently in middle-income countries as in low-income countries. Whether this is one reason for the correlation observed in this paper between recent poverty alleviation achievements and levels of development is unclear, however. It may also be that initial conditions matter: it is plausibly easier to reduce both absolute and relative poverty in countries where poverty is initially larger.

\footnotetext{
5 In 1999, CAR launched a "National Poverty Reduction Plan”, Ethiopia prepared an interim Poverty Reduction Strategy paper in November 2000, whereas a Poverty Reduction Strategy was launched in April 2002 in Malawi and in December 2003 in Mauritania.
} 
conomics: The Open-Access, Open-Assessment E-Journal

\section{Conclusion}

Poverty reduction has been recently brought to the fore of the analysis of the impact of growth on development. There indeed now prevails a wide consensus that both the rate and the distributional impact of growth are important in assessing its developmental role. This paper offers a method for assessing the joint absolute and relative distributive impact of growth through a bivariate test of the propoorness of growth.

Using this method, we are able to reconcile the absolute and relative approaches to assessing poverty and to determine whether distributional changes have been robustly pro-poor or anti-poor in nine African countries in the last fifteen years. Some of the countries, such as our four lower-income countries as well as Tunisia, have seen a robust fall in joint absolute and relative poverty. Other countries (Egypt, Mauritius, Morocco, and South Africa) have witnessed a fall in absolute poverty accompanied by a rise in relative poverty.

Overall, the paper's results reinforce the view that it is important to focus on individual country level experiences when analyzing the impact of growth. They are also consistent with the view that although economic growth often leads to a robust decline of absolute poverty, it can also simultaneously increase relative poverty. In many cases, therefore, whether distributive changes will be deemed to be good for the poor will depend on the manner in which the joint assessment of absolute and relative pro-poorness is performed. ${ }^{6}$

\footnotetext{
6 This work was carried out with support from the Poverty and Economic Policy (PEP) Research Network, which is financed by the Government of Canada through the International Development Research Centre (IDRC) and the Canadian International Development Agency (CIDA), and by the Australian Agency for International Development (AusAID). The paper was also inspired by the "Growth, Poverty and Inequality" study conducted by the Development Research Department of the African Development Bank. However, the views and interpretations in this paper reflect the opinions of the authors and not those of the African Development Bank, its Board of Directors or the countries they represent. We are grateful to Abdel-Rahmen El-Lahga and Naouel Chtioui for helpful comments and Mohamed Amara and Ines Bouassida for research assistance.
} 
conomics: The Open-Access, Open-Assessment E-Journal

\section{Appendix}

Figure A1 : Unidimensional poverty dominance curves
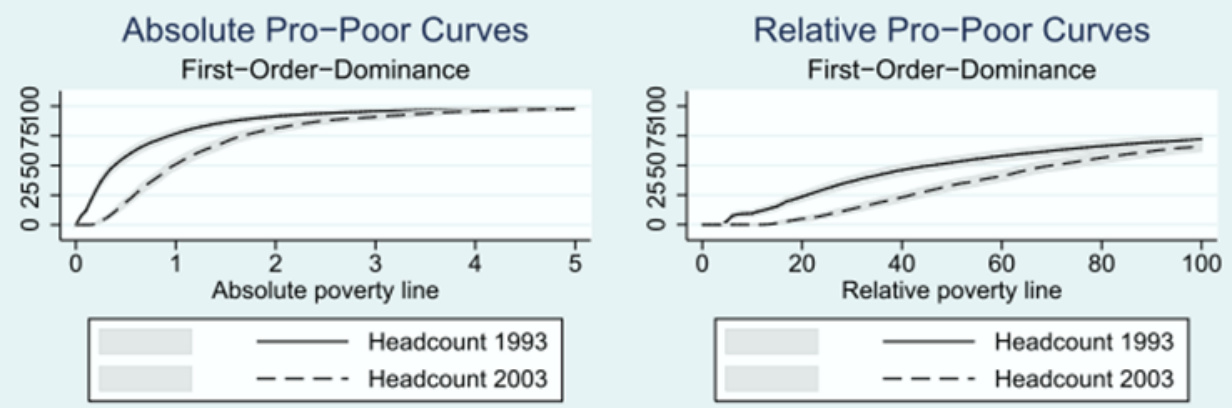

Difference in Absolute Poverty

First-Order-Dominance

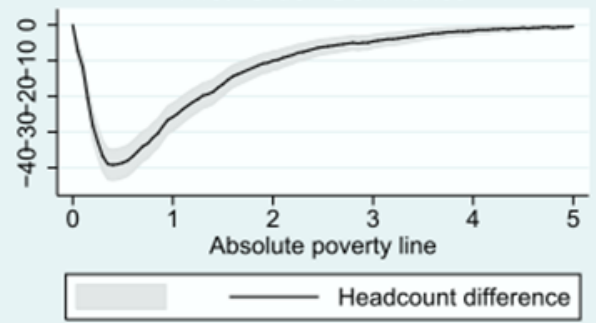

Difference in Relative Poverty First-Order-Dominance

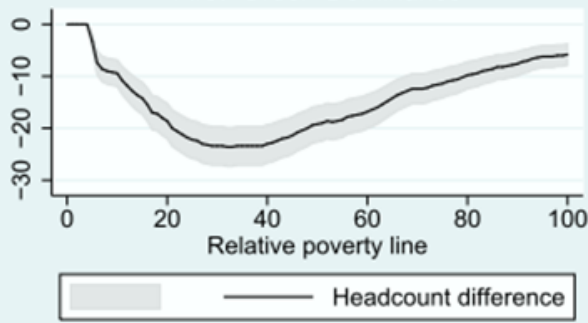

Note:

Central African Republic Povcal Lorenz ordinates 1993-2003 and the procedure of Shorrocks and Wan (2008) have been used to reconstruct individual data. 


\section{Economics: The Open-Access, Open-Assessment E-Journal}

Figure A2: Bidimensional growth dominance

Central Africa 1993-2003

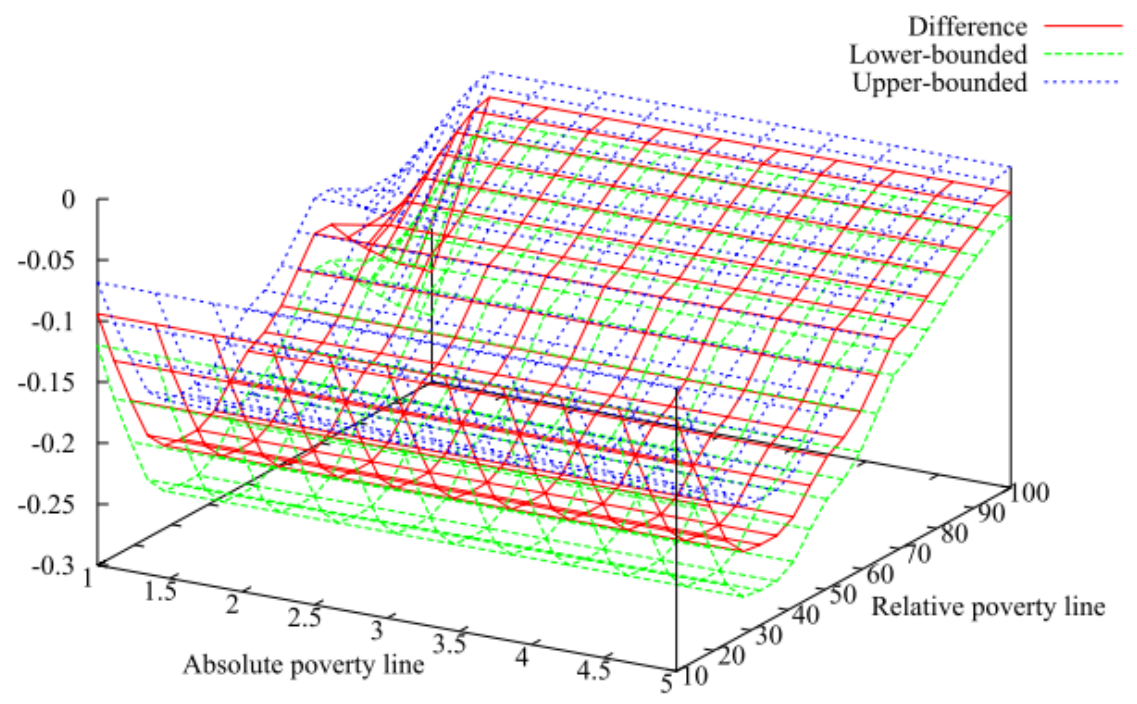

Note: Central African Republic Povcal Lorenz ordinates 1993-2003 and the procedure of Shorrocks and Wan (2008) have been used to reconstruct individual data. 
conomics: The Open-Access, Open-Assessment E-Journal

Figure A3: Unidimensional poverty dominance curves
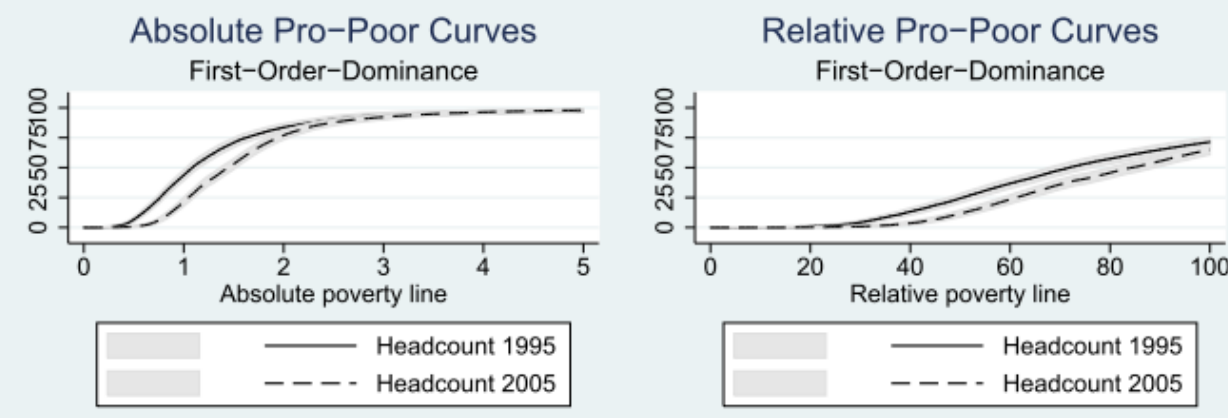

\section{Difference in Absolute Poverty}

First-Order-Dominance

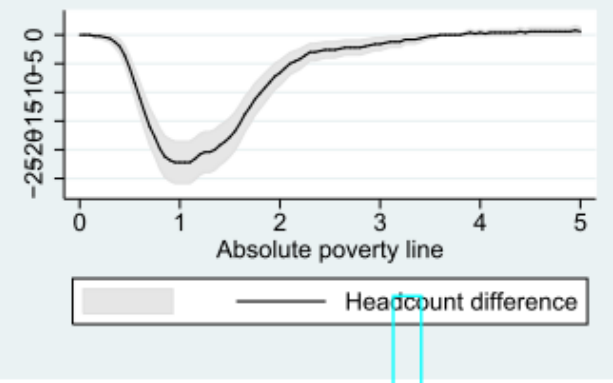

Difference in Relative Poverty First-Order-Dominance

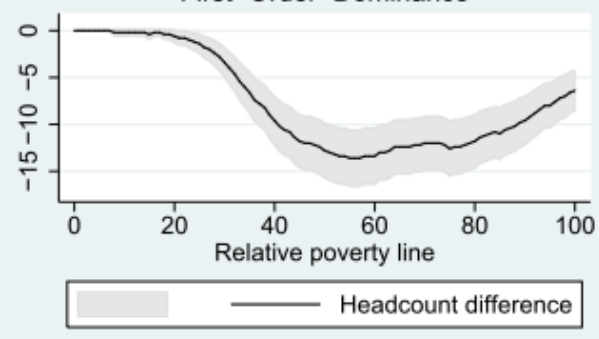

Note: Ethiopian Povcal Lorenz ordinates 1995-2005 and the procedure of Shorrocks and Wan (2008) have been used to reconstruct individual data. 


\section{Cconomics: The Open-Access, Open-Assessment E-Journal}

Figure A4: Bidimensional growth dominance curves

\section{Ethiopia 1995-2005}

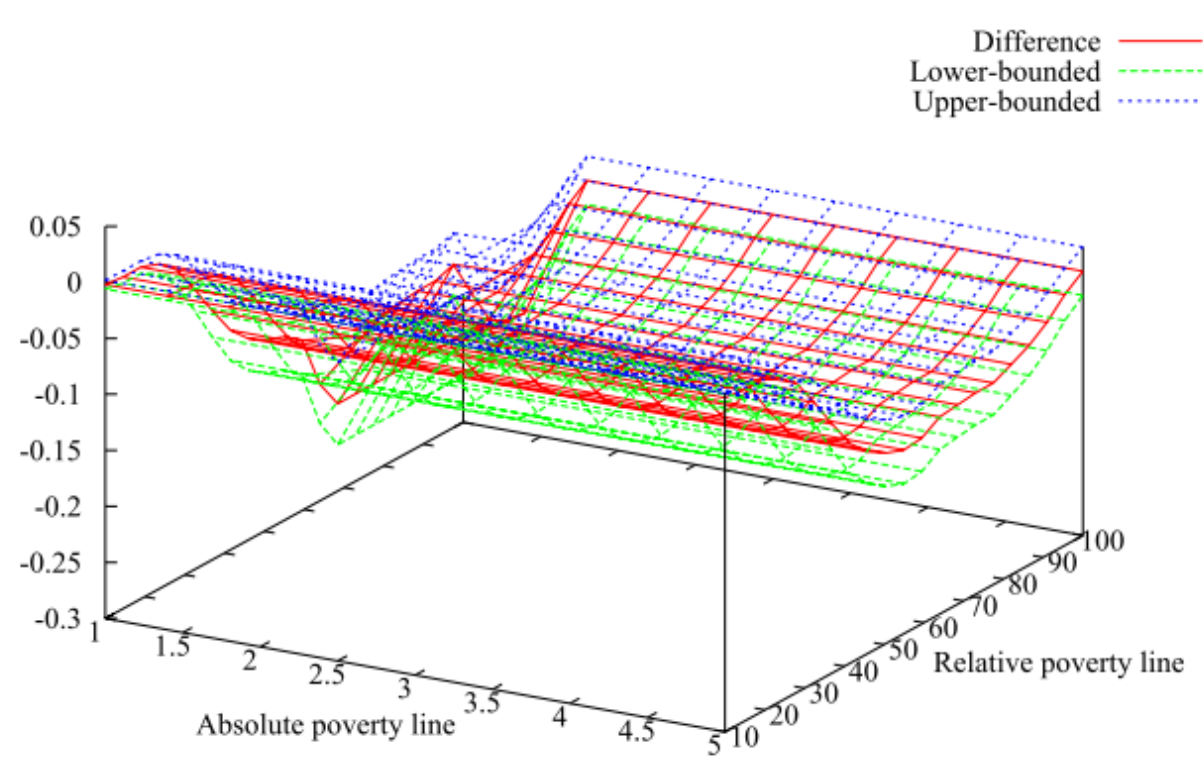

Note: Ethiopian Povcal Lorenz ordinates 1995-2005 and the procedure of Shorrocks and Wan (2008) have been used to reconstruct individual data. 
conomics: The Open-Access, Open-Assessment E-Journal

Figure A5: Unidimensional poverty dominance curves
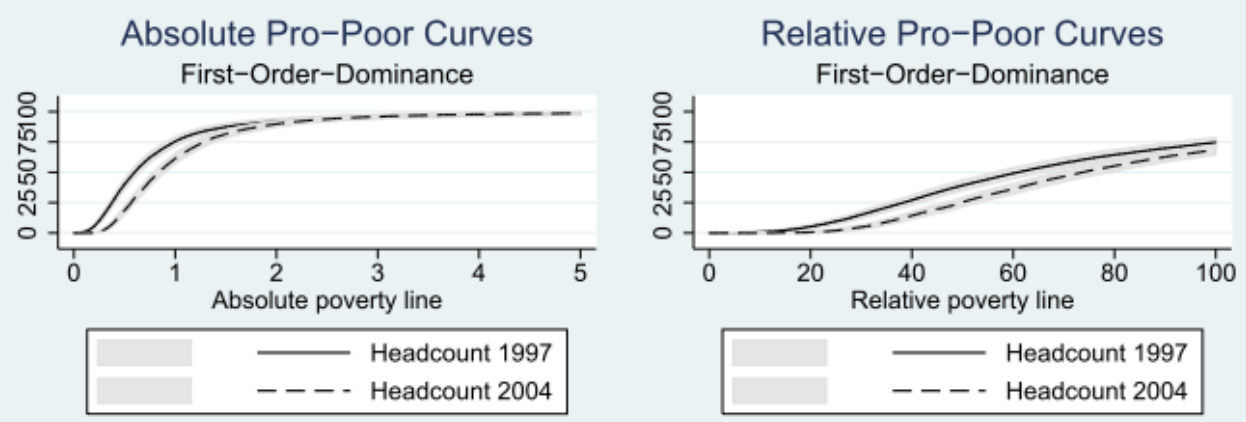

\section{Difference in Absolute Poverty} First-Order-Dominance

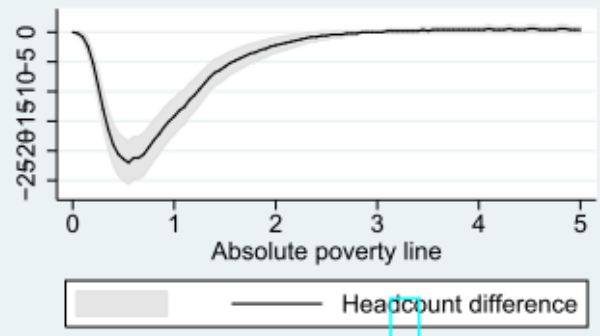

Difference in Relative Poverty First-Order-Dominance

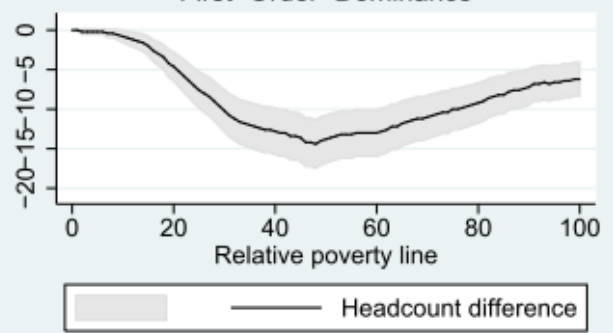

Note: Malawi Povcal Lorenz ordinates 1997-2004 and the procedure of Shorrocks and Wan (2008) have been used to reconstruct individual data. 


\section{Economics: The Open-Access, Open-Assessment E-Journal}

Figure A6: Bidimensional growth dominance curves

Malawi 1997-2004

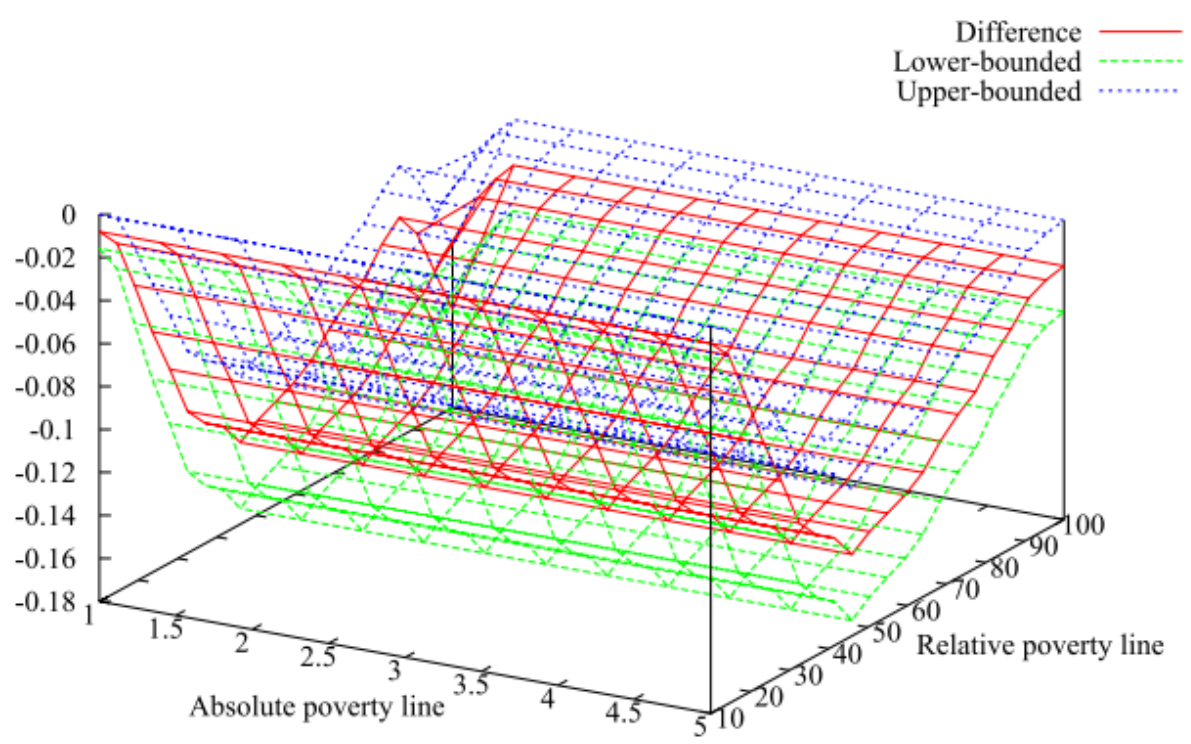

Note: Malawi Povcal Lorenz ordinates 1997-2004 and the procedure of Shorrocks and Wan (2008) have been used to reconstruct individual data. 
conomics: The Open-Access, Open-Assessment E-Journal

Figure A7: Unidimensional poverty dominance curves
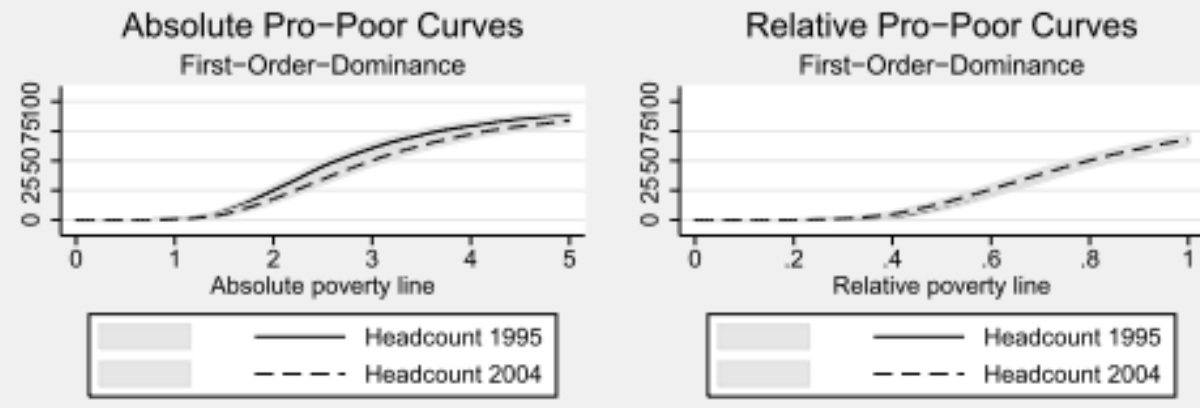

Difference in Absolute Poverty

First-Order-Dominance

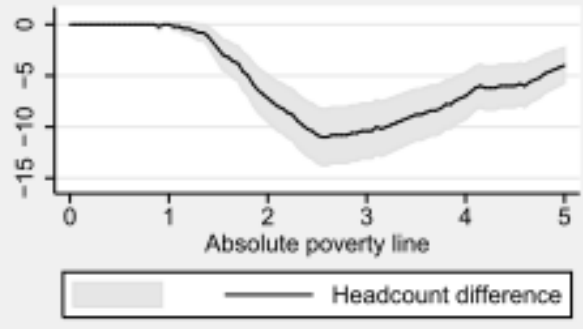

Difference in Relative Poverty

First-Order-Dominance

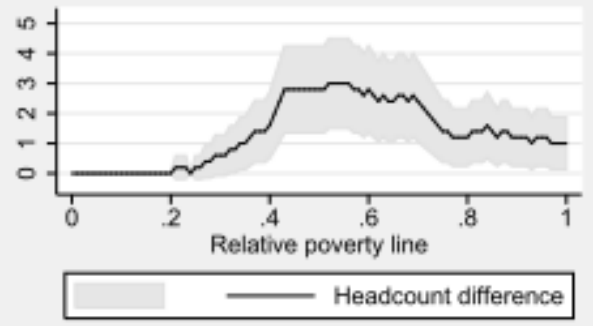

Note: Egyptian Povcal Lorenz ordinates 1995-2004 and the procedure of Shorrocks and Wan (2008) have been used to reconstruct individual data. 
Cconomics: The Open-Access, Open-Assessment E-Journal

Figure A8: Bidimensional growth dominance curves

Egypt 1995-2004

Difference

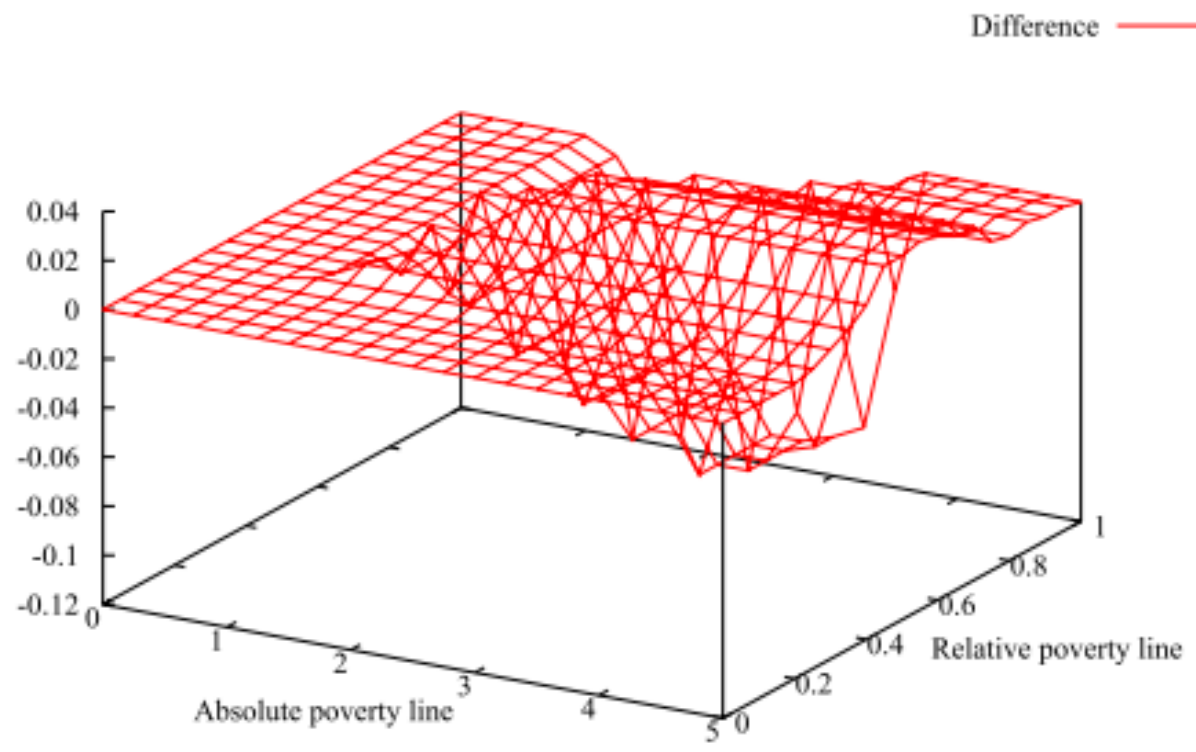

Note: Egyptian Povcal Lorenz ordinates 1995-2004 and the procedure of Shorrocks and Wan (2008) have been used to reconstruct individual data. 
conomics: The Open-Access, Open-Assessment E-Journal

Figure A9: Unidimensional poverty dominance curves
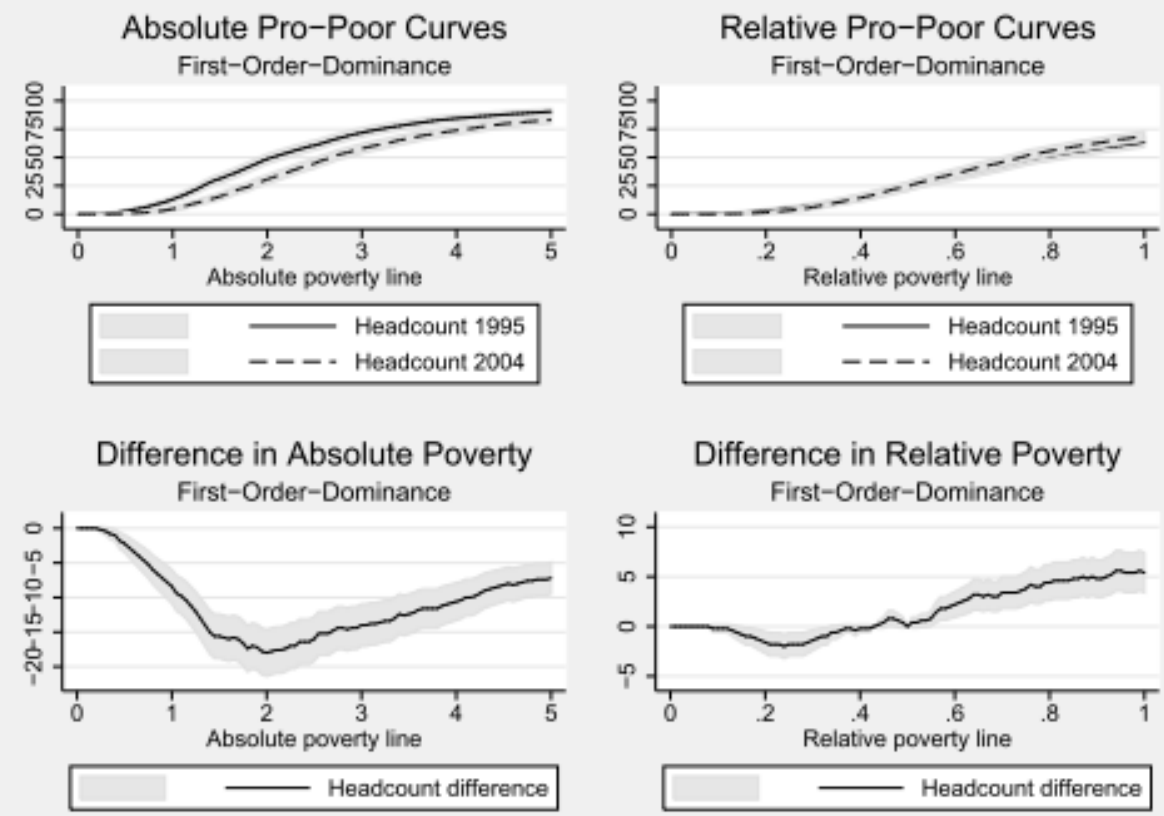

Note: Mauritanian Povcal Lorenz ordinates of 1995, Mauritanian Ministry of Economics and Development (2006), Lorenz ordinates of 2004, and the procedure of Shorrocks and Wan (2008) to reconstruct individual data. 


\section{Cconomics: The Open-Access, Open-Assessment E-Journal}

Figure A10: Bidimensional growth dominance curves

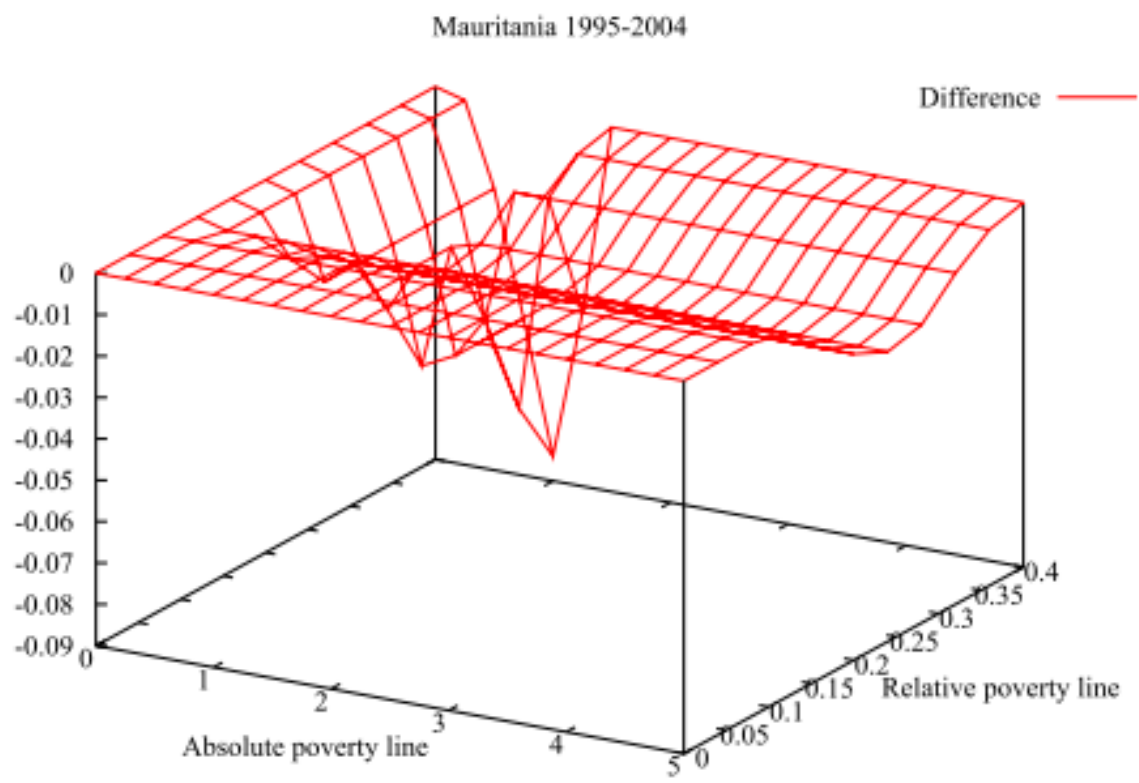

Note: Mauritanian Povcal Lorenz ordinates of 1995, Mauritanian Ministry of Economics and Development (2006), Lorenz ordinates of 2004, and the procedure of Shorrocks and Wan (2008) to reconstruct individual data. 
conomics: The Open-Access, Open-Assessment E-Journal

Figure A11: Unidimensional poverty dominance curves
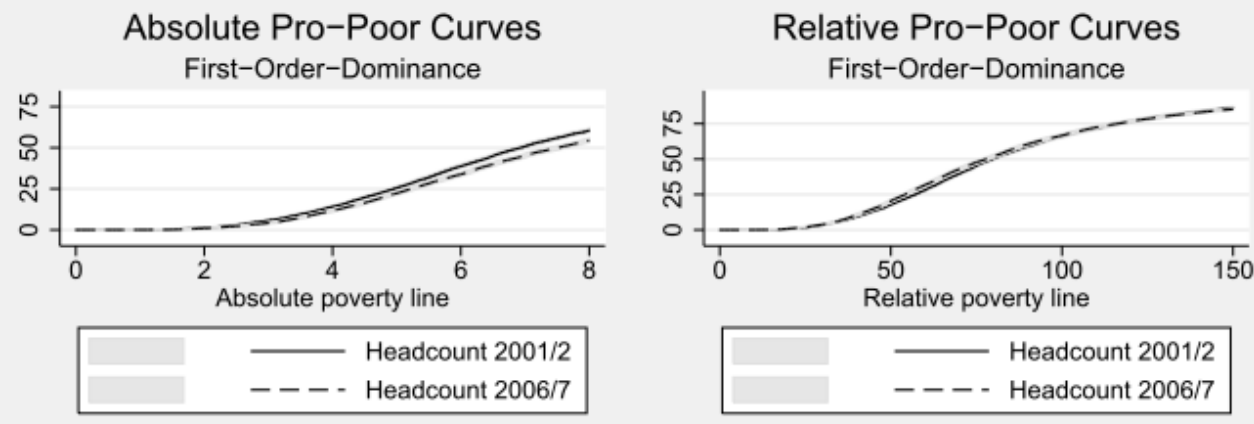

Difference in Absolute Poverty

First-Order-Dominance

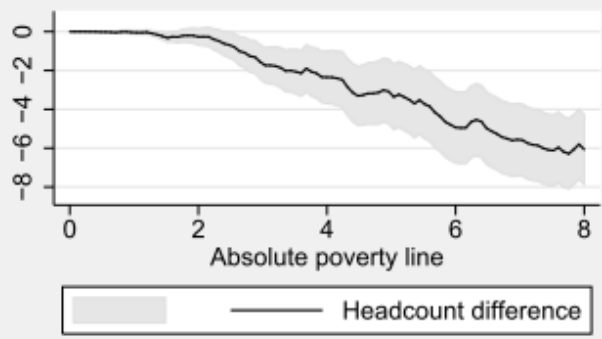

Difference in Relative Poverty First-Order-Dominance

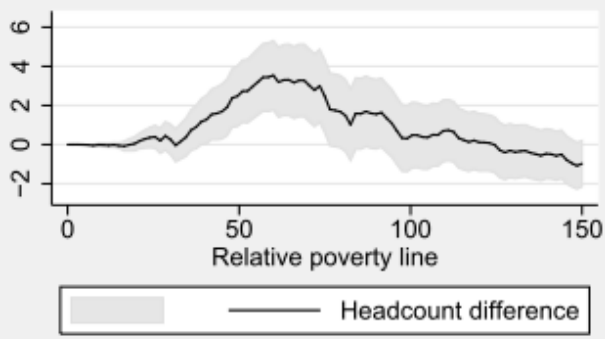

Note: Mauritius household surveys 2001/02-2006/07 have been used. 


\section{Conomics: The Open-Access, Open-Assessment E-Journal}

Figure A12: Bidimensional growth dominance curves

\section{Mauritius}

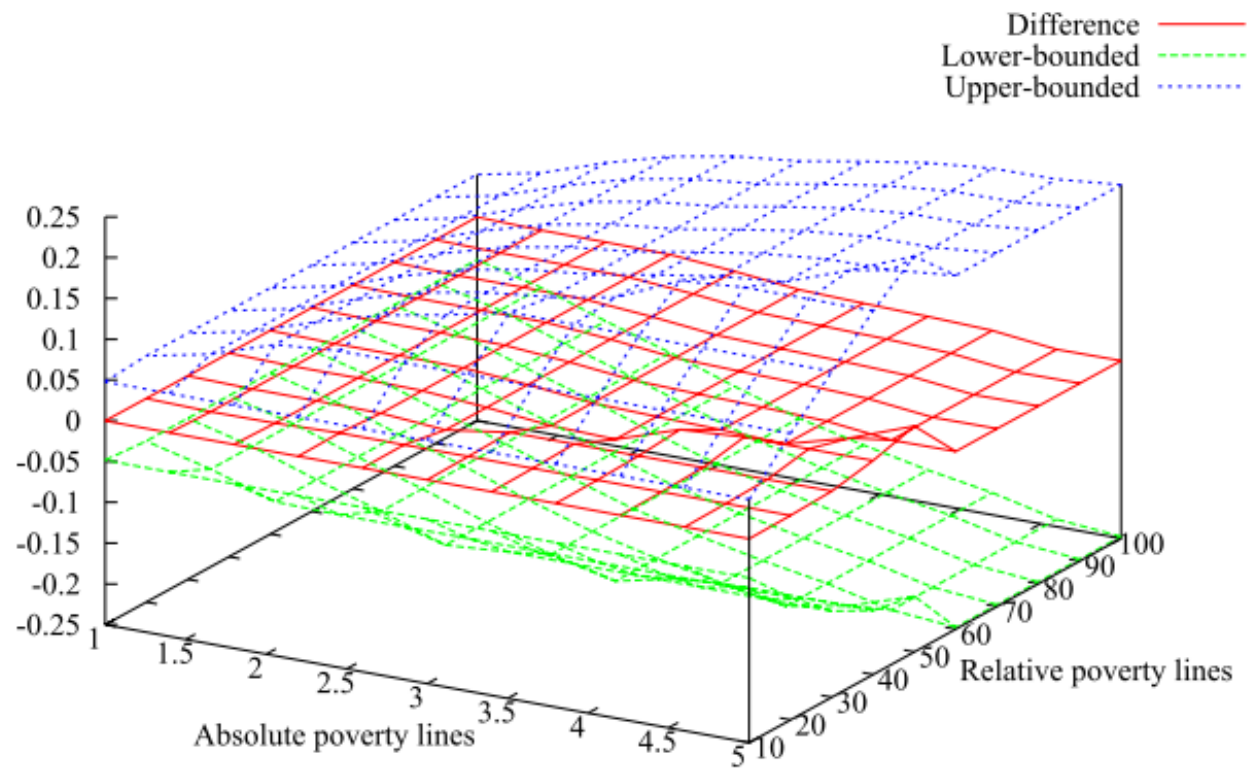

Note: Mauritius household surveys 2001/02-2006/07 have been used. 
conomics: The Open-Access, Open-Assessment E-Journal

Figure A13: Unidimensional poverty dominance curves
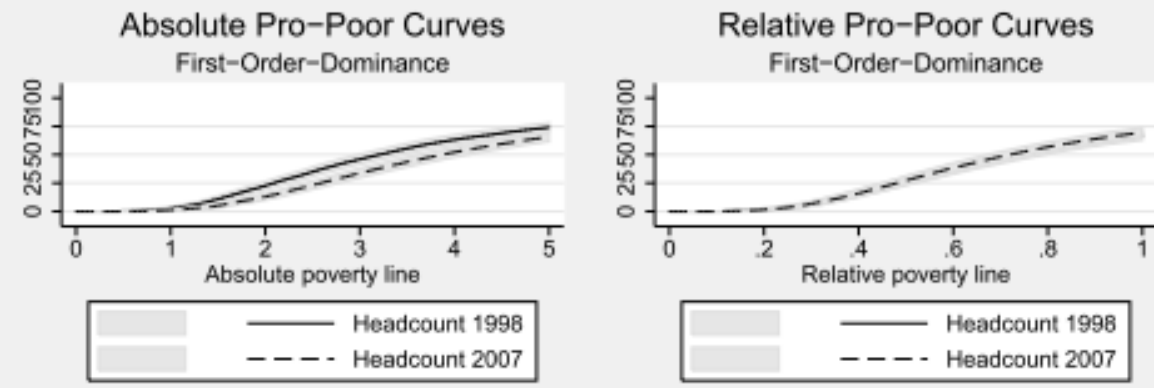

Difference in Absolute Poverty

First-Order-Dominance

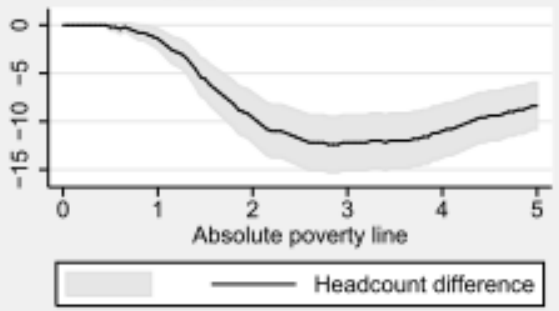

Difference in Relative Poverty

First-Order-Dominance

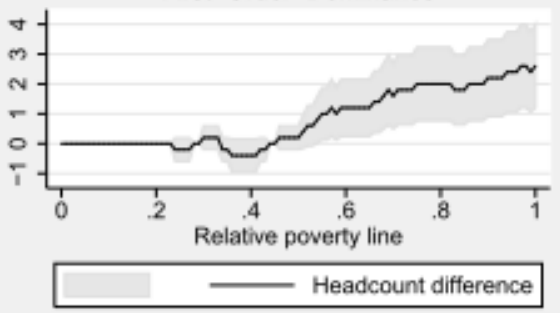

Note: Moroccan Povcal Lorenz ordinates 1998-2007 and the procedure of Shorrocks and Wan (2008) have been used to reconstruct individual data. 


\section{Economics: The Open-Access, Open-Assessment E-Journal}

Figure A14: Bidimensional growth dominance curves

Morocco 1998-2007

Difference

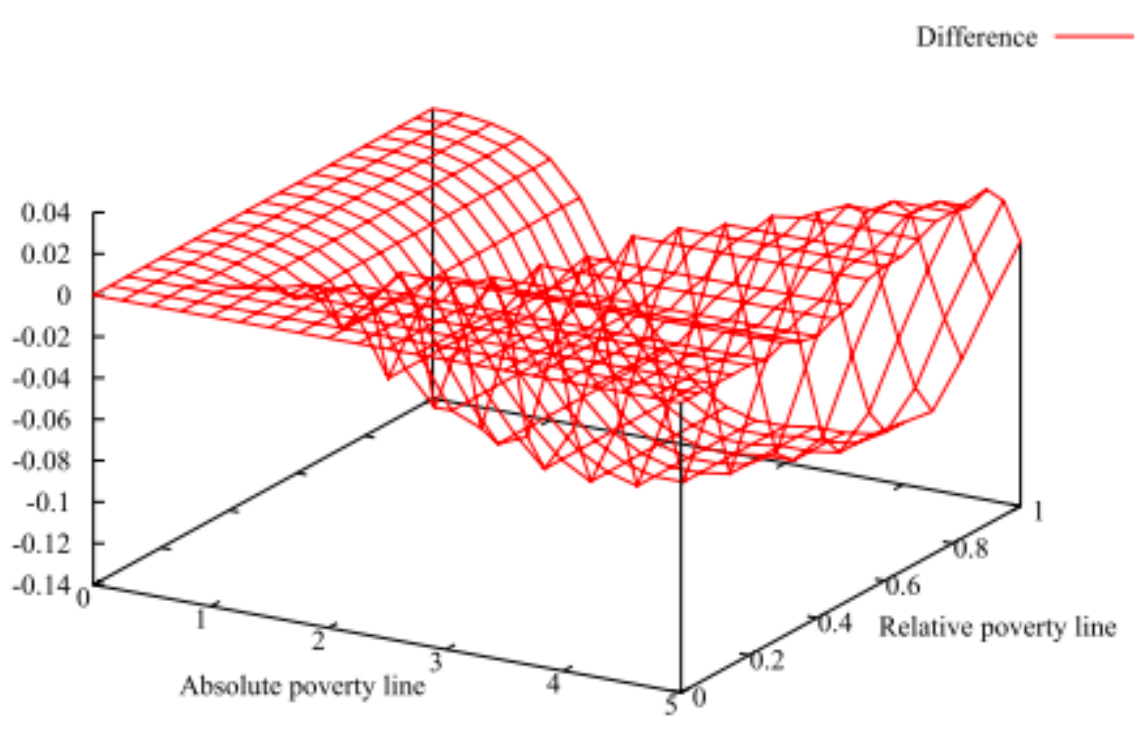

Note: Moroccan Povcal Lorenz ordinates 1998-2007 and the procedure of Shorrocks and Wan (2008) have been used to reconstruct individual data. 
conomics: The Open-Access, Open-Assessment E-Journal

Figure A15: Unidimensional poverty dominance curves
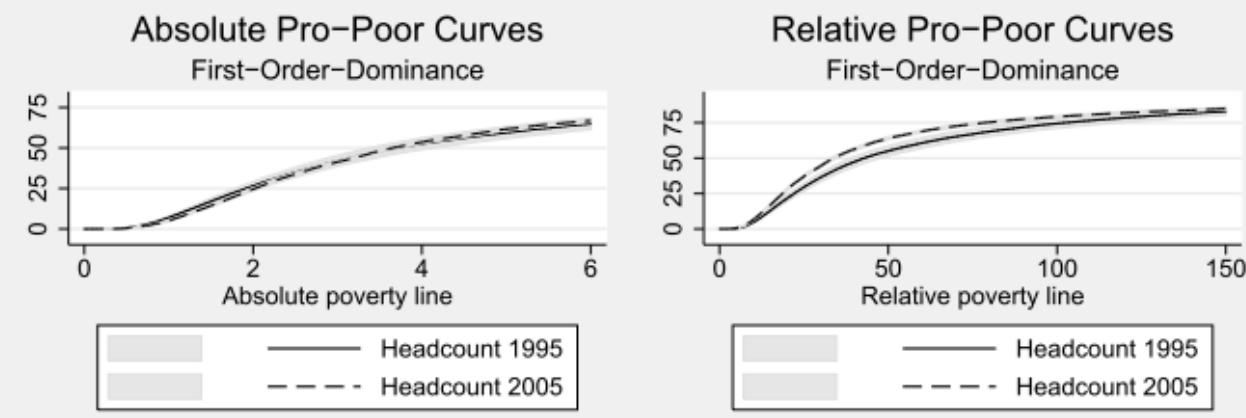

Difference in Absolute Poverty First-Order-Dominance

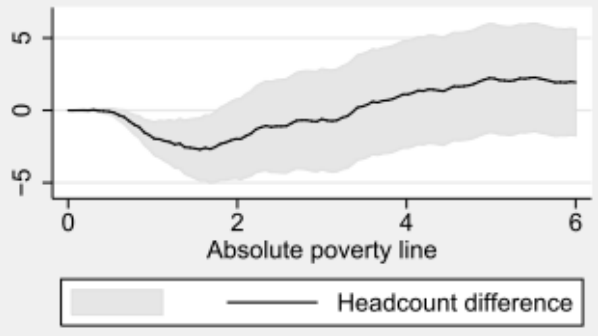

Difference in Relative Poverty First-Order-Dominance

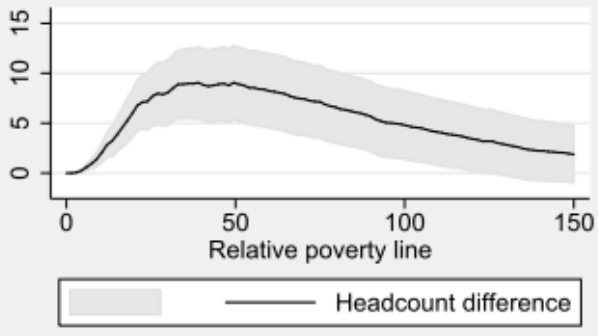

Note: South African household surveys 1995-2005 have been used. 


\section{Economics: The Open-Access, Open-Assessment E-Journal}

Figure A16: Bidimensional growth dominance curves

\section{South-Africa}

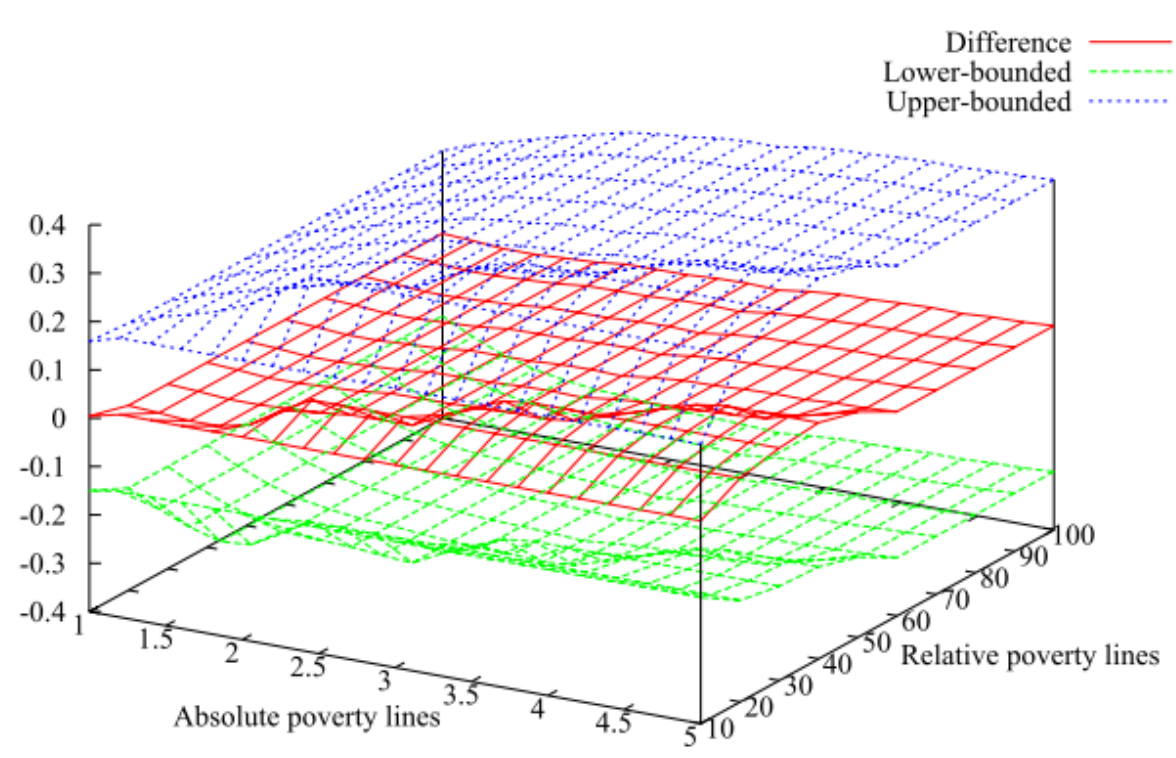

Note: South African household surveys 1995-2005 have been used. 
conomics: The Open-Access, Open-Assessment E-Journal

Figure A17: Unidimensional poverty dominance curves
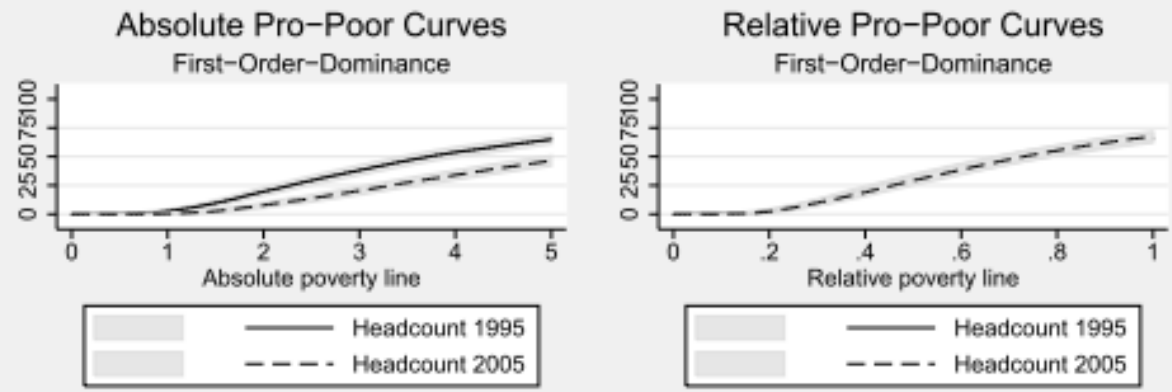

Difference in Absolute Poverty First-Order-Dominance

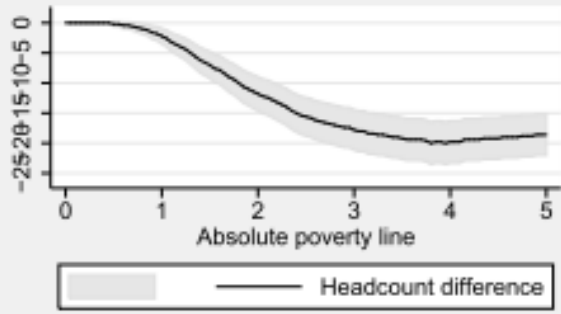

Difference in Relative Poverty First-Order-Dominance

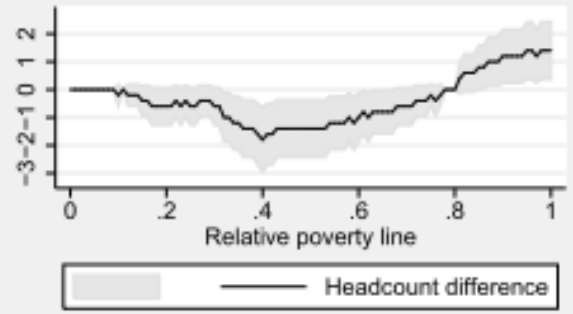

Note: Tunisian Povcal Lorenz ordinates of 1995, Tunisian National Institute of Statistics (2007), Lorenz ordinates of 2005, and the procedure of Shorrocks and Wan (2008) have been used to reconstruct individual data. 


\section{Economics: The Open-Access, Open-Assessment E-Journal}

Figure A18: Bidimensional growth dominance curves

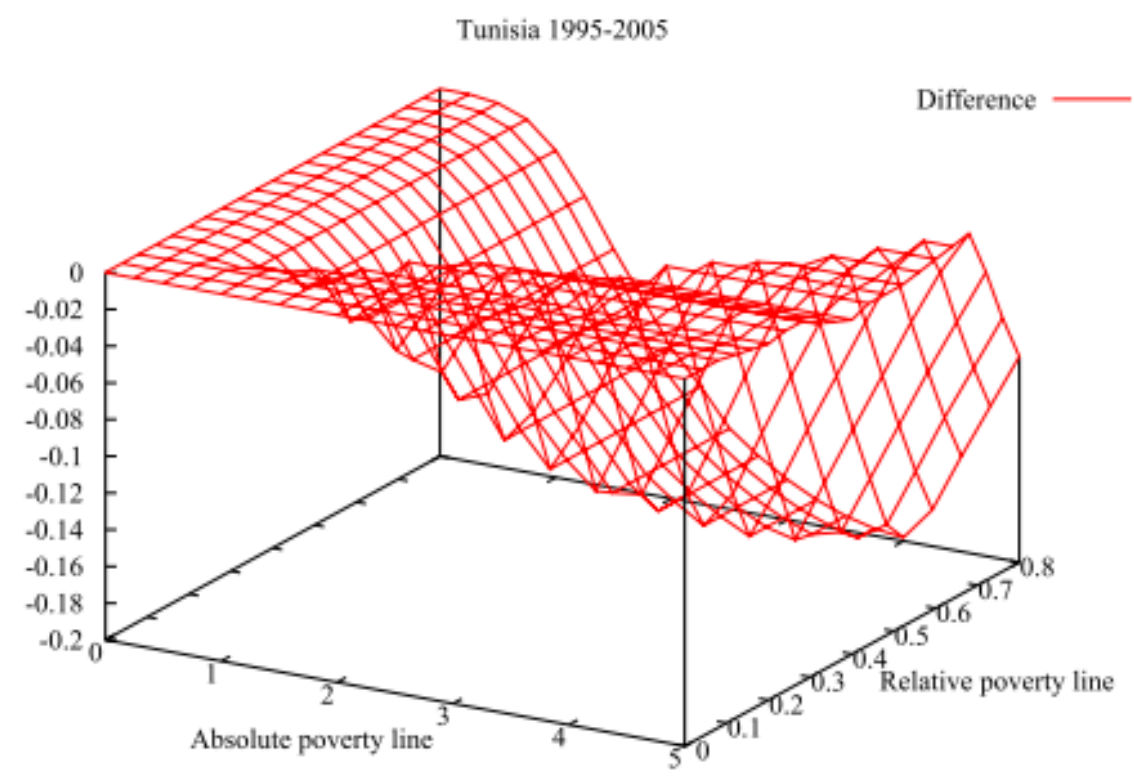

Note: Tunisian Povcal Lorenz ordinates of 1995, Tunisian National Institute of Statistics (2007), Lorenz ordinates of 2005, and the procedure of Shorrocks and Wan (2008) have been used to reconstruct individual data. 
conomics: The Open-Access, Open-Assessment E-Journal

\section{References}

African Development Bank (2010). Growth, Poverty and Inequality in Selected African Middle-Income Countries. Development Research Department. Mimeo.

Alkire, S. and J. E. Foster (2011). Counting and Multidimensional Poverty Measurement. Journal of Public Economics 95: 476-487.

http://ideas.repec.org/a/eee/pubeco/v95y2011i7-8p476-487.html

Araar, A. and J.-Y. Duclos (2007). DASP: Distributive Analysis Stata Package. PEP, CIRPEE and World Bank, Université Laval.

http://132.203.59.36/DASP/modules/DASP_V2.1/DASP_MANUAL_V2.1.pdf

Araar, A., J.-Y. Duclos, M. Audet, and P. Makdissi (2009). Testing for propoorness of growth, with an application to Mexico. Review of Income and Wealth 55: 853-881.

http://ideas.repec.org/a/bla/revinw/v55y2009i4p853-881.html

Bibi, S, J.-Y. Duclos and A. Verdier-Chouchane (2010).:Assessing Absolute and Relative Pro-Poor Growth: An Application to the MENA Region. Working Paper 111. African Development Bank, Tunis, Tunisia.

http://ideas.repec.org/p/adb/adbwps/248.html

Bibi, S. and M. K. Nabli (2009). Income Inequality in the Arab Region: Data and Measurement, Patterns and Trends. Middle East Development Journal 1: 275314. http://ideas.repec.org/a/wsi/medjxx/v01y2009i02p275-314.html

Bourguignon, F. and S. Chakravarty (2003). The Measurement of Multidimensional Poverty. Journal of Economic Inequality 1: 25-49.

http://ideas.repec.org/a/kap/jecinq/v1y2003i1p25-49.html

Bourguignon, F. (2004). The Poverty-Growth-Inequality Triangle. Working Paper 125. Indian Council for Research on International Economic Relations, New Delhi, India. http://ideas.repec.org/p/ind/icrier/125.html

Chen, S., G. Datt, and M. Ravallion (1994). Is Poverty Increasing in the Developing World? Review of Income and Wealth 40: 359-376.

http://ideas.repec.org/a/bla/revinw/v40y1994i4p359-76.html 
Collier, P., and Dollar, D. (2001). Globalization, Growth and Poverty: Building an Inclusive World Economy. Policy Research Reports. World Bank; Oxford University Press USA.

http://publications.worldbank.org/index.php?main_page=product_info\&cPath $=0 \&$ products_id=22001

Dollar, D. and A. Kraay (2002). Growth Is Good for the Poor. Journal of Economic Growth 7: 195-225.

http://ideas.repec.org/a/kap/jecgro/v7y2002i3p195-225.html

Duclos, J.-Y. (2009). What is 'Pro-Poor'? Social Choice and Welfare 32: 37-58. http://ideas.repec.org/a/spr/sochwe/v32y2009i1p37-58.html

Duclos, J.-Y., D. E. Sahn, and S. D. Younger (2006). Robust Multidimensional Poverty Comparison. Economic Journal 116: 943-968. http://ideas.repec.org/a/ecj/econjl/v116y2006i514p943-968.html

Eastwood, R. and M. Lipton (2001). Pro-poor Growth and Pro-Growth Poverty Reduction: What do they Mean? What does the Evidence Mean? What can Policymakers do? Asian Development Review 19: 1-37.

IMF, OECD, United Nations, and World Bank (2000). A Better World for All. Washington, Paris, New York.

http://www.imf.org/external/pubs/ft/jointpub/world/2000/eng/bwae.pdf

Institut National de la Statistique (2007) Enquête Nationale sur les Dépenses, la Consommation, et le Niveau de Vie des Ménages en 2005. Tech. rep., Ministère du Développement et de la Coopération Internationale, Tunisia.

Kakwani, N., S. Khandker, and H. Son (2003). Poverty Equivalent Growth Rate: With Applications to Korea and Thailand. Technical Report, Economic Commission for Africa.

http://info.worldbank.org/etools/BSPAN/PresentationView.asp?EID=194\&PI $\mathrm{D}=383$

Kakwani, N. and E. Pernia (2000). What is Pro-Poor Growth? Asian Development Review 18: 1-16.

http://www2.adb.org/documents/periodicals/adr/adr_vol_18_1.pdf

Klasen, S. (2004). In Search of the Holy Grail: How to Achieve Pro-Poor Growth? In: Toward Pro Poor Policies-Aid, Institutions, and Globalisation, ed. by B. Tungodden, N. Stern, and I. Kolstad, New York: Oxford University Press. 
Ministère des Affaires Economiques et du Développement (2006). Profil de la Pauvreté en Mauritanie-2004. Technical Report, Commissariat aux Droits de l'Homme, à la Lutte contre la Pauvreté et à l'Insertion, Mauritania.

http:/www.economie.gov.mr/NR/rdonlyres/B3779277-472C-445C-A2DA87E36AEF666C/0/Profil_Pauv_2004.pdf

Ravallion, M. (2001). Growth, Inequality and Poverty: Looking Beyond Averages. World Development, 29, 1803-1815.

http://ideas.repec.org/a/eee/wdevel/v29y2001i11p1803-1815.html

Ravallion, M. and S. Chen (2003). Measuring Pro-poor Growth. Economics Letters 78: 93-99. http://ideas.repec.org/a/eee/ecolet/v78y2003i1p93-99.html

Sen, A. (1981). Poverty and Famine: An Essay on Entitlement and Deprivation. Clarendon Press, Oxford University Press.

Shorrocks, A. and G. Wan (2008). Ungrouping Income Distributions: Synthesising Samples for Inequality and Poverty Analysis. Working paper, UNU-WIDER, http://ideas.repec.org/p/unu/wpaper/rp2008-16.html.

UNDP (2009). IPC-IG Collection of One-Pagers, International Policy Centre for Inclusive Growth, Brazil.

http://www.ipc-undp.org/pub/IPCOnePagerBook.pdf

World Bank (2008). Global Purchasing Power Parities and Real Expenditures: 2005 International Comparison Programme. Technical Report, Washington. http://siteresources.worldbank.org/ICPINT/Resources/icp-final.pdf 


\section{Conomics}

The Open-Access, Open-Assessment E-Journal

Please note:

You are most sincerely encouraged to participate in the open assessment of this article. You can do so by either recommending the article or by posting your comments.

Please go to:

http://dx.doi.org/10.5018/economics-ejournal.ja.2012-7

The Editor 